\title{
Disturbance of wildlife by outdoor winter recreation: allostatic stress response and altered activity-energy budgets
}

\author{
Raphä̈l Arlettaz, ${ }^{1,2,3,7}$ Sébastien Nusslé, ${ }^{1,4}$ Marjana Baltic, ${ }^{1}$ Peter Vogel, ${ }^{5,8}$ Rupert Palme, ${ }^{6}$ \\ Susanne Jenni-Eiermann, ${ }^{2}$ Patrick Patthey, ${ }^{1}$ and Michel Genoud ${ }^{1,5}$ \\ ${ }^{1}$ Division of Conservation Biology, Institute of Ecology and Evolution, University of Bern, Baltzerstrasse 6, CH-3012 Bern, Switzerland \\ ${ }^{2}$ Swiss Ornithological Institute, $\mathrm{CH}-6204$ Sempach, Switzerland \\ ${ }^{3}$ Grupo de Investigaciones de la Biodiversidad, IADIZA, CONICET-CCT, Av. Ruiz Leal, Parque General San Martín, Mendoza, \\ Argentina \\ ${ }^{4}$ Department of Environmental Science, Policy and Management, University of California, Berkeley, California $94720-3114$ USA \\ ${ }^{5}$ Department of Ecology and Evolution, Biology Building, University of Lausanne, CH-1015 Lausanne, Switzerland \\ ${ }^{6}$ Institute of Medical Biochemistry, Department of Biomedical Sciences, University of Veterinary Medicine, Vienna; Veterinärplatz 1, \\ A-1210 Vienna, Austria
}

\begin{abstract}
Anthropogenic disturbance of wildlife is of growing conservation concern, but we lack comprehensive approaches of its multiple negative effects. We investigated several effects of disturbance by winter outdoor sports on free-ranging alpine Black Grouse by simultaneously measuring their physiological and behavioral responses. We experimentally flushed radio-tagged Black Grouse from their snow burrows, once a day, during several successive days, and quantified their stress hormone levels (corticosterone metabolites in feces $[\mathrm{FCM}]$ collected from individual snow burrows). We also measured feeding time allocation (activity budgets reconstructed from radio-emitted signals) in response to anthropogenic disturbance. Finally, we estimated the related extra energy expenditure that may be incurred: based on activity budgets, energy expenditure was modeled from measures of metabolism obtained from captive birds subjected to different ambient temperatures. The pattern of FCM excretion indicated the existence of a funneling effect as predicted by the allostatic theory of stress: initial stress hormone concentrations showed a wide inter-individual variation, which decreased during experimental flushing. Individuals with low initial pre-flushing FCM values augmented their concentration, while individuals with high initial FCM values lowered it. Experimental disturbance resulted in an extension of feeding duration during the following evening foraging bout, confirming the prediction that Black Grouse must compensate for the extra energy expenditure elicited by human disturbance. Birds with low initial baseline FCM concentrations were those that spent more time foraging. These FCM excretion and foraging patterns suggest that birds with high initial FCM concentrations might have been experiencing a situation of allostatic overload. The energetic model provides quantitative estimates of extra energy expenditure. A longer exposure to ambient temperatures outside the shelter of snow burrows, following disturbance, could increase the daily energy expenditure by $>10 \%$, depending principally on ambient temperature and duration of exposure. This study confirms the predictions of allostatic theory and, to the best of our knowledge, constitutes the first demonstration of a funneling effect. It further establishes that winter recreation activities incur costly allostatic behavioral and energetic adjustments, which call for the creation of winter refuge areas together with the implementation of visitor-steering measures for sensitive wildlife.
\end{abstract}

Key words: alpine ecosystems; birds; Black Grouse; corticosterone metabolites; energy allocation modeling; noninvasive stress monitoring; Tetrao tetrix; tourism; winter recreation.

\section{INTRODUCTION}

The tourism industry increasingly advertises leisure activities in the wilderness of remote areas, with extreme outdoor sports and ecotourism becoming an important source of income worldwide. Ecotourism alone is

Manuscript received 14 June 2014; revised 4 November 2014; accepted 10 November 2014. Corresponding Editor: J. R. Goheen.

${ }^{7}$ E-mail: raphael.arlettaz@iee.unibe.ch

${ }^{8}$ Deceased. See Acknowledgments. estimated to contribute $9 \%$ of global gross domestic product, representing a market of USD $\$ 6$ trillion in 2011 (INTOSAI [International Organization of Supreme Audit Institutions] WGEA 2013). Nature recreation, however, has recently been recognized as a new, serious threat to ecosystems (Taylor and Knight 2003, Munns 2006, Sutherland 2007). Already faced with habitat degradation, endangered species of wildlife must contend with additional problems likely to impact physiology and population dynamics, including stress (Arlettaz et al. 2007, Rehnus et al. 2014), energetics 
(Williams et al. 2006)], behavior (Baines and Richardson 2007, Thiel et al. 2008), reproductive performance (Watson and Moss 2004, Langston et al. 2007), survival (Müllner et al. 2004), and abundance (Hofer and East 1998, Watson and Moss 2004, Patthey et al. 2008). Yet there are few studies that have simultaneously investigated the repercussions generated by recreational disturbance, from mounting a stress response, to reallocating time and energy, to changes in physiological condition, immunological competence, reproductive ability, and survival (Carey 2005, Stevenson 2006). Ideally, all these aspects should be understood to suggest adequate mitigation strategies, which must account for actual tolerance thresholds vis à vis anthropogenic disturbance (Sutherland 2007).

Mounting a stress response is believed to be an energetically demanding physiological process for the organism (Hofer and East 1998, Svensson et al. 1998, Von der Ohe and Servheen 2002, Schummer and Eddleman 2003). The ability of an individual to cope with stress strongly depends on several physiological factors, such as body condition, age, reproductive status, gender (Wingfield et al. 1995, Wasser et al. 1997, Goymann et al. 2002, Millspaugh and Washburn 2004, Touma and Palme 2005), and even habituation to predictable or unpredictable stressors (Wingfield et al. 1997, Fowler 1999). Yet little is known about the energy trade-off between response to stress and other life history components (e.g., physiological balance and reproduction) in free-ranging animals. To overcome a stressful event, it is crucial to restore homeostasis (sensu McEwen and Wingfield 2003) as quickly as possible. This may first be achieved by increasing the foraging rate or prolonging foraging bouts in situ (Bélanger and Bédard 1990, Brodin 2001, Reneerkens et al. 2002), or by moving to richer foraging grounds (Wingfield et al. 1997). Second, artificial prolonging of resting periods, while lowering the metabolic rate, has also been observed (Wingfield and Silverin 1986). Third, mobilizing one's own energetic reserves (e.g., fat deposits, muscle proteins) is another option (Schmidt-Nielsen 1990, Sapolsky et al. 2000, Brodin 2001). In any case, the inability to restore homeostasis leads inevitably towards an allostastic overload, i.e., physiological weakening of the organism, starvation, easy susceptibility to predators and pathogens and, eventually, death (Möstl and Palme 2002, Watson and Moss 2004).

The costs of mounting a stress response and being pushed to allostatic overload likely are greater for boreal and alpine species of birds and mammals that have only limited fat and protein reserves during winter (Thomas 1987, Willebrand and Marcström 1989, Stokkan 1992). As these species depend on a regular access to food, they have a particularly sensitive energetic balance, which renders them more susceptible to disturbances stemming from outdoor recreation (Thomas 1987). Critically, wildlife inhabiting mountainous areas increasingly are exposed to winter outdoor recreation, even in remote places far from ski resorts (Arlettaz et al. 2007, Braunisch et al. 2011, Rehnus et al. 2014).

The aim of this study was to investigate the behavioral and physiological consequences of human disturbance by snow sports on Black Grouse (Tetrao tetrix; see Plate 1). Black Grouse is a declining key indicator species of boreo-alpine ecosystems in Eurasia (Storch 2007). In the European Alps, its semi-open habitat lies within the subalpine timberline belt, mainly between 1700 and 2300 $\mathrm{m}$ altitude, where most skiing infrastructure and outdoor recreation is concentrated (Patthey et al. 2008, Braunisch et al. 2011), thereby exposing them to anthropogenic disturbance (Arlettaz et al. 2007). In winter, alpine Black Grouse show a bimodal daily activity rhythm, with periods of foraging in early morning and late afternoon (hereafter evening) (Marjakangas 1986). These two phases usually last a total of 2.5-3.5 h, although they may be shorter under severe weather conditions (Pauli 1974, Bossert 1980). Most of the day is spent in snow burrows ("igloos"), which appears to be an efficient anti-predator and energysaving strategy (Marjakangas 1986, Spidsø et al. 1997), although we lack quantitative assessments of energetic constraints and limits in this species. Since Black Grouse dig a new igloo after each foraging bout (i.e., two igloos per day), it is possible to collect fecal samples to carry out noninvasive stress hormone investigations (Baltic et al. 2005, Arlettaz et al. 2007). Moreover, fecal material is conserved at low temperatures in the snow, thus impeding bacterial and enzymatic degradation of the hormones and/or their metabolites (Baltic et al. 2005). Consequently, Black Grouse are an ideal model for studying the physiological impact of anthropogenic disturbance on alpine wildlife.

The effects of anthropogenic disturbance by outdoor winter sports (e.g., on-piste and off-piste skiing, backcountry skiing, snow-shoeing [see Arlettaz et al. 2007]) were simulated by a back-country skier (one field technician) experimentally flushing radio-tagged Black Grouse from their snow burrows, once a day, during several successive days, thereby mimicking a series of real disturbance episodes. We first measured birds' physiological response noninvasively, through the analysis of fecal corticosterone (bird stress hormone) metabolites (FCM). We tested for a physiological response to human disturbance based on the allostatic theory framework (see McEwen and Wingfield 2003) and its recent extension (Romero et al. 2009). Allostasis is defined as the series of physiological adjustments that aim at achieving stability in the internal milieu of an organism. In other terms, it consists of all the physiological changes that organisms make to cope with a fluctuating environment (Landys et al. 2006). Therefore, allostasis is the sum of all physiological processes and adjustments that stabilize basic vital functions in the face of environmental change.

Both predictable and stochastic events may induce an allostatic load associated with an increase of glucocor- 
Energy available to cope with predicted changes in the environment (regulated allostasis)

Energy available for basic maintenance (homeostasis)

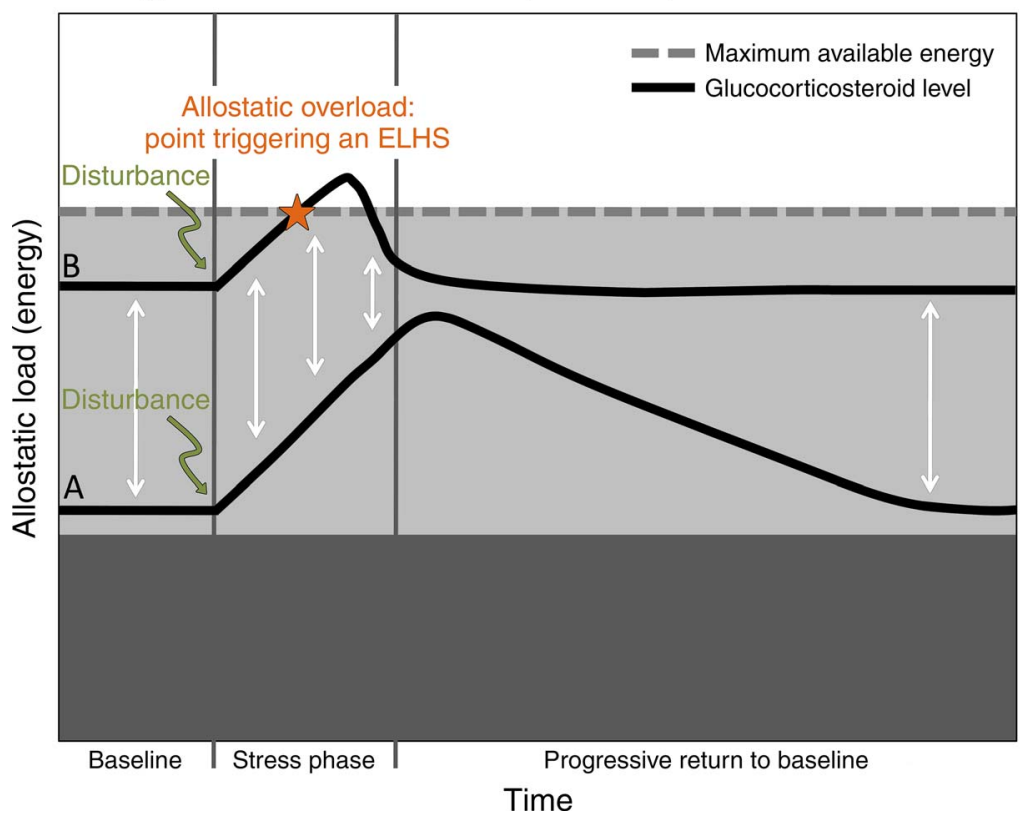

FIG. 1. Schematic representation of a funneling effect on FCM concentrations, as derived from the allostatic theory of stress, after a disturbance event (green arrows) has generated a stress response in the organism. Depicted is the energy available in the environment; dark gray: energy available for basic maintenance; light gray: energy available to cope with predicted changes in the environment, i.e., regulated allostasis. The dashed line shows the upper limit of energy availability in the environment. Bird A has low initial glucocorticoid levels, contrary to bird B. Both birds increase glucocorticoid production at a similar pace after disturbance (green curved arrows), but bird B rapidly overshoots the upper threshold of energy availability (allostatic overload limit), which triggers an Emergency Life History Stage (ELHS) that rapidly suppresses other life history stages to return to manageable regulated allostasis, i.e., a more balanced energy budget. This pattern would result in birds with high and low initial values to converge in their glucocorticoid levels following disturbance. This convergence represents the "funneling effect," i.e., a narrower variation (expressed by the ranges of the white vertical arrows) in FCM concentrations after disturbance (corresponding to our experimental flushing treatment; see Fig. 2) than before it.

ticoid secretions whose role is to supply the organism with the energy necessary to overcome the stressful situation. Usually, predictable events do not pose a problem because available energy is sufficient to perform allostatic adjustments. However, when the energy supply becomes too low to optimally cope with change, allostatic overload occurs, which typically triggers an emergency life history stage (ELHS) in the organism (Fig. 1). This means that sufficient glucocorticoid production may then be achieved or maintained, since mounting a stress response impairs energetic costs, only if the organism trades it off against other vital functions, i.e., if it diminishes the energy it invests in other life history processes (e.g., maintenance, immune function, growth, and reproduction). This unstable situation can only be temporary, however, as such energy reallocation otherwise comes at the cost of long-term survival, growth, and reproduction. By negative feedback mechanisms, corticosterone release is therefore reduced, which diminishes the energy required to overcome the stressful situation, allowing for reallocation to vital functions that had been compromised during the allostatic overload phase. Whether or not an organism faces an allostatic overload situation, i.e., is experiencing an ELHS, is ultimately dictated by the amount of energy that can be extracted from the environment. These allostatic adjustments thus serve to return the animal to a positive energy balance, increasing long-term chances of survival.

Within this framework, we therefore expected that birds with low initial (i.e., before our disturbance experiment) concentration of FCM would show an increase of FCM concentration (Arlettaz et al. 2007). In contrast, the trend in FCM concentration would be different in birds that already exhibited high initial FCM concentrations, due to either natural (e.g., exposure to predators or adverse weather [Raouf et al. 2006]) or anthropogenic factors. If a bird's allostatic load was already close to the overload limit (including an individual being in an "over-shoot" situation, not represented in Fig. 1; sensu McEwen and Wingfield 2003), and its initial FCM concentrations were already relatively high, then we would expect a rapid decrease of FCM, given that an ELHS has been triggered. Reaction to disturbance can thus be seen as a bi-directional process, with birds' responses varying according to their initial physiological ("stress") state, which may depend on both environmental context and animal personality 
(e.g., Careau et al. 2008). Thus, given the expected variation in individual initial exposure and response to stress (for reasons mentioned above; see also Arlettaz et al. 2007), we predicted a high inter-individual variation in FCM concentration before the onset of the experiment (pre-flushing phase), and a decrease of FCM variation during experimental disturbance (provoked flushings), followed by a progressive return to a greater interindividual variation (similar to the pre-flushing phase) after disturbance (here corresponding to flushing several days in a row) had ceased. Due to the shape of this variation along the experimental sequence, this pattern is here termed a "funneling effect."

In parallel to measures of FCM concentrations, and during the same experiments, we quantified changes in activity pattern and time allocation (foraging vs. resting) as well as variation of energy budgets. We predicted (1) that disturbance induces prolongation of foraging sessions because of the need to compensate for any energy losses induced by the disturbance, especially given the reduced fat stores of Black Grouse (Thomas 1987, Willebrand and Marcström 1989); and (2) that any compensatory feeding may alter the finely tuned winter eco-physiological balance. To the best of our knowledge, this study represents one of the first attempts to investigate simultaneously several effects of winter outdoor recreation on wildlife while testing the predictions of the allostatic theory, namely the existence of a funneling effect, in a free-ranging species. The resulting information is crucial to better understanding the impact of winter outdoor recreation on wildlife and to suggesting appropriate mitigation and conservation measures.

\section{Material And Methods}

Study area, study species, and disturbance experiments

Male Black Grouse were mist-netted on leks in May 2002-2003 in Verbier-Bruson $\left(46^{\circ} 05^{\prime} \mathrm{N}, 7^{\circ} 15^{\prime} \mathrm{E}\right)$, Champoussin $\left(46^{\circ} 12^{\prime} \mathrm{N}, 6^{\circ} 51^{\prime} \mathrm{E}\right)$, Les Diablerets $\left(46^{\circ} 19^{\prime}\right.$ $\left.\mathrm{N}, 7^{\circ} 07^{\prime} \mathrm{E}\right)$, and Entremont $\left(45^{\circ} 58^{\prime} \mathrm{N}, 7^{\circ} 11^{\prime} \mathrm{E}\right)$ in the southwestern Swiss Alps. Twelve birds were tagged with 15-g neck-laced radio-transmitters equipped with an activity sensor (Holohil Systems Limited, Carp, Canada), under license of the Wildlife and Game services of the Cantons of Valais and Vaud, and of the Swiss Confederation. Our study sites were potentially exposed to free-ride activities (back-country skiers, snowboarders, and snowshoers) as spatially predicted in the conflict model by Braunisch et al. (2011), but no disturbance other than our experimental flushings was recorded during our activities. We only used males so as to minimize the potentially confounding effect of gender, as stress and sex hormones often interact (Husak and Moore 2008).

All disturbance experiments were carried out between early January and mid-March in 2003, 2004, and 2006, well before the onset of the mating season in the Alps (mostly end of May) to avoid confounding interactions between stress and sex hormones. Radio-tagged birds were experimentally and individually flushed from their snow burrows once a day, always between 14:00 and 15:00, by an observer approaching them on skis. The approach was direct (targeting the radio signal), mimicking that of a sportsperson (skier, snowboarder, snowshoer) inadvertently flushing a bird resting in a snow burrow. An experiment consisted of a series of flushings during four consecutive days, followed by a last flushing three days after the end of this series (Fig. 2). We distinguished three experimental phases: preflushing (initial baseline), experimental flushing (experimental treatment), and post-flushing (final "baseline," within quotation marks because there was actually no return to initial values, see Results and Discussion).

\section{Stress response}

Droppings were collected from igloos after each targeted flushing of a radio-tagged bird. The fecal material collected during the first flushing event constitutes our pre-flushing initial baseline (day 0), as these samples stemmed from birds that had not yet been experimentally disturbed. (For more details about the stress hormone excretion pattern, see Fig. 2 and Baltic et al. [2005], Arlettaz et al. [2007].). The three following 24 h-periods (starting at 14:00) were our (disturbance through flushing) experimental treatment (days 1-3). A post-flushing, final "baseline" consisted of the droppings collected in the same way during a last flushing event (called day 4) which took place a few (at least three) days after the last flushing day of the series in a row (i.e., after treatment day 3), and thus includes fecal material that would theoretically mirror the level of stress experienced by a bird three or more days after the experimental flushing had ceased. Overall, the fecal material collected from an igloo on a given day (all droppings from an igloo constituted our statistical unit, giving bird $\times$ day samples) yields integral information about FCM concentration during a period of up to 18$24 \mathrm{~h}$ prior to a flushing event (for more details, see Fig. 2 and Baltic et al. [2005], Arlettaz et al. [2007]). The droppings were kept frozen, first in the field on carbonic ice (dry ice), then deep frozen at $-22^{\circ} \mathrm{C}$, to avoid enzymatic degradation (Baltic et al. 2005).

The feces do not contain corticosterone per se, but some of its metabolites (FCM, fecal corticosterone metabolites). FCM were quantified with a group-specific cortisone enzyme immunoassay (EIA) that measures corticosterone metabolites with a 3,11-dione structure. (For details of the EIA, including cross-reactions, see Rettenbacher et al. [2004].) The assay has been successfully validated for measuring FCM in Black Grouse (Baltic et al. 2005). Droppings were homogenized and dried to constant mass $\left(3 \mathrm{~h}\right.$ at $\left.70^{\circ} \mathrm{C}\right)$. From each of the 47 igloo samples collected, 2-34 subsamples (0.5 g each; see Appendix: Table A1) were randomly selected, their final number depending on the quantity of fecal material per sample. FCM were extracted (Palme 

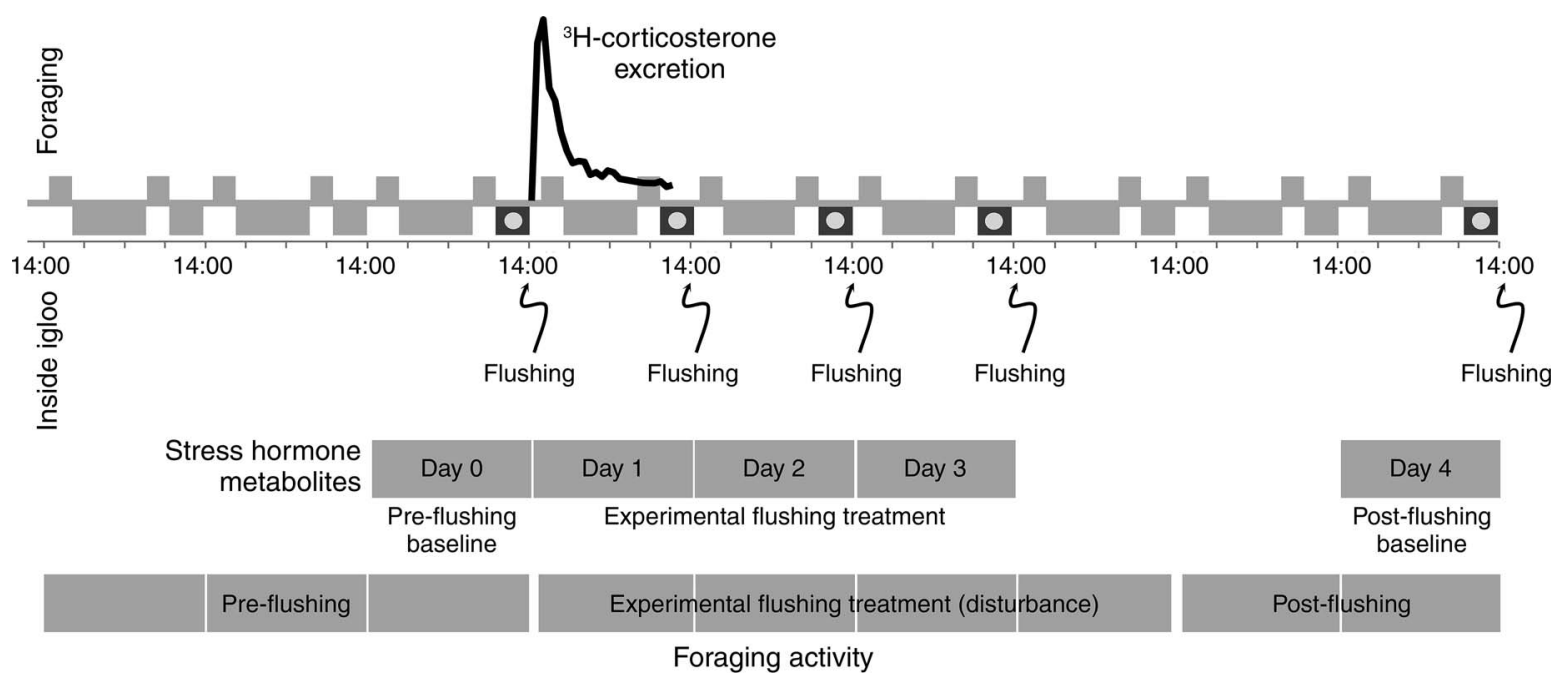

FIG. 2. Sampling design for flushing experiments. The light gray-shaded blocks show the approximate average duration of morning (dawn) and evening (dusk) foraging bouts (above the $x$-axis, which depicts time) and of igloo resting (below the same axis) in our free-ranging, experimentally disturbed Black Grouse. The arrows depict approximate time of flushing and feces collection. The dark gray blocks marked with a circle indicate the period during which fecal material collected for the analysis was deposited inside snow burrows. For validation of the assay (Baltic et al. 2005), radio-labelled corticosterone $\left({ }^{3} \mathrm{H}\right.$-corticosterone) was injected into caged Black Grouse. Thereafter the droppings were collected once per hour. The analysis of ${ }^{3} \mathrm{H}$-corticosterone reflects the expected temporal excretion pattern of FCM (as depicted by the black curve) here presented only for the first flushing. The three main phases (pre-flushing, experimental flushing treatment, post-flushing) are presented for the stress and the time-budget analysis, respectively. For more details refer to the text (extended from Arlettaz et al. 2007).

et al. 2013) from these subsamples in $60 \%$ methanol. Extracts were diluted 1:10 in assay buffer ( $\mathrm{pH} 7.5)$. EIA analysis was performed as described in detail by Rettenbacher et al. (2004) with microtiter plates. EIA sensitivity was $10 \mathrm{ng} / \mathrm{g}$, while the inter-assay coefficients of variation of high and low concentration pools were below $10 \%$ (Busso et al. 2013). All FCM samples $(n=$ 499) were analyzed in duplicates (if necessary they were repeated until $<10 \%$ variation between duplicates was reached). Concentrations of all samples were above the detection limit. FCM levels, measured in nanograms per gram of dry feces, derived strongly from Gaussian distribution and therefore were $\log _{e}$-transformed for data normalization.

According to the allostatic theory of stress, the pattern of stress hormone excretion should display a funneling effect, i.e., a decreased variance during stressful situations compared to normal (see Fig. 1). To test for this funneling effect we estimated, and compared, the variance in stress response between control and treatment (pre-flushing, used as a baseline control; experimental stress treatment [flushing events]; and post-flushing) with a mixed-effects model approach (Pinheiro and Bates 2000). We modeled the response to disturbance (log-transformed FCM concentrations) as a function of fixed effects (time and treatment), and random effects (bird identity) to account for repeated measurements per bird [12 birds, 3-5 flushings per bird (four birds were flushed 3 times, five birds were flushed 4 times, and three birds were flushed 5 times), average of 10.5 FCM subsamples per flushing]. We obtained pre- flushing and flushing samples from all birds. Four birds, however, could not be sampled for post-flushing due to their relocation to dangerous terrain (risk of avalanche). Mixed-models methodology allows missing data to be estimated for random effects, as the estimation is based on variance calculation (Bates 2010). We were thus able to model the contribution of these four birds to the postflushing "baseline," even though we did not resample them in that last experimental phase. As FCM excretion was influenced by season, with a negative curvilinear effect corresponding to progressively increasing hormone levels at the beginning of the year followed by a decrease from around mid-February (Fig. 3), our model included a quadratic term for the Julian date (day 1 is 1 January) to adjust for this seasonal effect. In other words, the analyses were performed on seasonally corrected FCM values. Preliminary analyses showed no effect of the year of sampling, and therefore the factor year was not included in the model. Fixed effects were assessed with a likelihood ratio test between an initial model, including all effects, and reduced models that did not include the specific effect.

Random effects were computed for all three experimental phases, i.e., in each phase every bird received a single value that indicated its stress level compared to the average stress level in each phase. This random effects variation is not independent between treatments, and therefore classical $F$ tests (ratio test) are likely to be inaccurate (Lee 1992). To bypass this problem, we therefore compared the variance in individual stress response (random effects) between the experimental 
phases with a permutated $F$ test (ratio test), i.e., we randomly resampled our data set 10000 times to obtain an empirical distribution for variance in random effects (in all three experimental phases). Then we computed the variance ratios in each new sample, i.e., for each random sample we divided the variance in the pre-flushing phase by (1) the variance in the flushing phase; and (2) the variance in the post-flushing phase; while we also (3) divided the variance in the flushing phase by the variance in the post-flushing phase. The null hypothesis of the permutation test, that variance does not differ between two phases, would imply that $\sim 50 \%$ of the variance ratios would be greater (or smaller) than one. The probability that these ratios were larger (or smaller) than one thus represents a test of whether the variance in stress response is larger (respectively smaller) in the different phases.

To estimate the individual responses (trajectories) to stress, we modeled, for each bird, but this time without accounting for the phases, a linear regression of FCM concentrations as a function of time (time here expressed as the number of days following initial disturbance). The slope of the regression thus quantifies for each bird the average stress response trajectory (direction, i.e., increased or decreased, and amplitude in FCM change over time) after several episodes of disturbance. We compared these trajectories to the pre-flushing baseline FCM values (the intercept of the linear regression) in order to detect a potential link between the average FCM response and the initial baseline stress level.

All analyses were performed using the open access software R (R Development Core Team 2012) and the package lme4 (Bates et al. 2011).

\section{Activity budget}

Each bird's activity was monitored via the activity sensor of the radio tags, with recordings starting 1-3 days before the first flushing and ceasing after the last flushing event. The 24-h periods before the first flushing served as the pre-flushing baseline (no disturbance by observer; Fig. 2), while the four 24-h periods from the first flushing to $24 \mathrm{~h}$ after the fourth flushing of the sequence of four flushings in a row constituted our experimental treatment (Fig. 2). Finally, the three 24-h periods between the fourth flushing and the fifth flushing represented our post-flushing "baseline," which followed a short period without disturbance by the observer (Fig. 2). We used stationary radio-receiving data-loggers (TR5, Telonics, Mesa, Arizona, USA) with monopole aerials to register active signal date and time. Data were standardized to allow for comparison of activity patterns across days and birds. The absolute number of active signals recorded per interval of 10-min duration served as a basis. By dividing those 10-min figures by the total number of recordings per day, we obtained relative curves of signal pulse rates, which were an excellent approximation of an activity pattern (Appendix: Fig. A1). Regular visual observation of radio-tracked birds provided a validation that behavior could be encoded in a simple dichotomic way: foraging or resting. In effect, we systematically took the opportunity (during field visits, notably while controlling the electronic radio-monitoring equipment) to assess bird behavior: birds were either resting (including self-grooming) or foraging, without any other type of behavior observed, such as agonistic or sexual interactions. Then, we considered as foraging bouts every single 10 -min time interval falling above a $4 \%$ threshold of overall daily relative activity, as well as any cluster of three or more 10-min intervals in a row with values $>1 \%$ (referring back to the field visual observation of radiotagged birds). Simple, binary activity budgets could then be drawn, enabling the estimation of the duration of resting, as well as morning and evening foraging bouts, for every bird and day (Appendix: Fig. A1).

The effect of experimental disturbance on foraging activity was tested with a mixed-effects model analysis and a Markov-Chain Monte Carlo (MCMC) approach for $P$ value estimation (Bates et al. 2011). The experimental phase (pre-flushing; experimental treatment, i.e., disturbance through flushings elicited by ourselves; and post-flushing; Fig. 2) was used as a fixed term, whereas bird identity was used as a random term to account for repeated measurements (12 birds, 3-5 flushings per bird). The overall experimental phase effect was tested with a likelihood-ratio test between the model including the experimental phase and a null model. Post hoc tests were also performed to look at pairwise differences between the experimental phases. Morning and evening foraging bouts were considered separately as the birds seemed to react differently between dawn and dusk. There was in fact a significant seasonal effect with an increased duration of evening foraging bouts of $0.63 \pm 0.24$ foraging minutes per Julian day (mean \pm $\mathrm{SE}$ ) over the season (linear regression: $t=2.59, \mathrm{df}=71$, $\left.r^{2}=0.07, P=0.01\right)$. On the contrary, we found no significant change $(0.27 \pm 0.19$ minutes $)$ with regard to morning foraging bouts (linear regression: $t=1.43, \mathrm{df}=$ $\left.71, r^{2}=0.01, P=0.16\right)$. We thus tested the difference between the three experimental phases in the evening with the residuals of the linear regression, while the difference between treatments in the morning were assessed with the real foraging time, as no seasonal effect was detected.

We finally compared foraging activity to baseline stress levels in order to estimate if the response to stress could influence foraging activity (only 10 birds were used for that analysis). We used linear regression with log-transformed FCM as an explanatory variable and the total foraging duration as a response variable.

All analyses were performed using the open access software R (R Development Core Team 2012) and the package lme4 (Bates et al. 2011).

\section{Energetics}

Our goal was to quantify any extra energy expenditure incurred by free-ranging Black Grouse following 


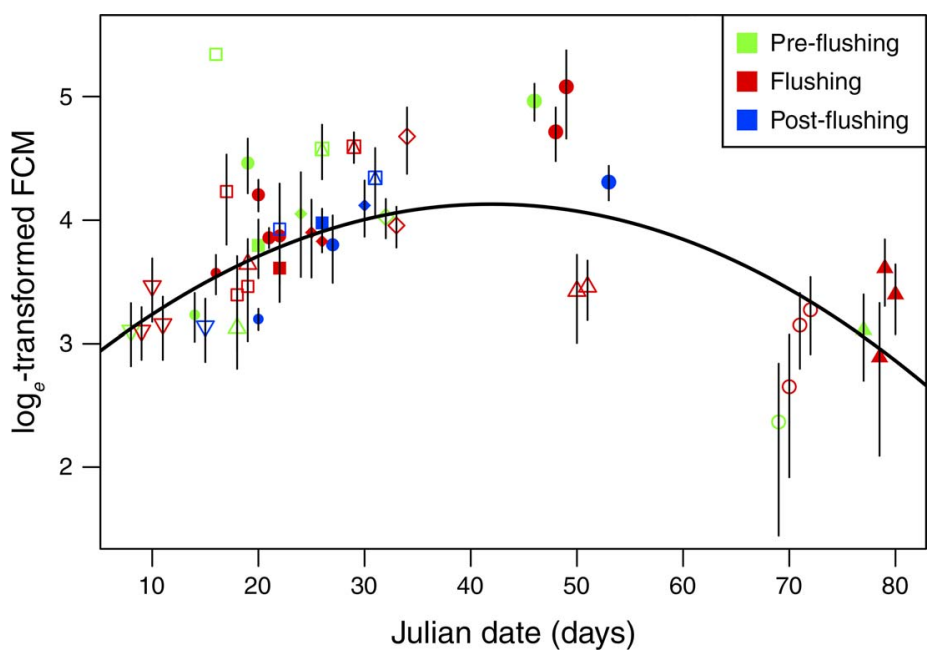

FIG. 3. Mean ( $\pm \mathrm{SD}$, before $\log _{e}$-transformation) individual stress hormone concentrations ( $\log _{e}$-transformed fecal corticosterone metabolites $[\mathrm{FCM}]$ expressed as $\mathrm{ng} / \mathrm{g}$ ) in relation to Julian date, showing the quadratic effect of season that had to be accounted for in the analyses of stress response and foraging duration. Different birds are depicted by different symbols, while colors represent the three experimental phases. The black curve represents the expected value of FCM.

anthropogenic disturbance. During the field observations carried out to establish the activity budget, the daily mean ambient temperature ranged between $-11.2^{\circ} \mathrm{C}$ and $9.3^{\circ} \mathrm{C}$; thus we focused our modeling on a range of ambient temperature from $-15^{\circ} \mathrm{C}$ to $10^{\circ} \mathrm{C}$. As measuring rates of metabolism directly in the field is not feasible in this species, we had to rely on laboratory respirometric measurements obtained from captive birds subjected to various ambient temperatures $\left(T_{\mathrm{a}}\right)$ and to reconstruct daily energy expenditure based on activity patterns recorded in the field (Activity budget), accounting for variation in $T_{\mathrm{a}}$. The temperatures $\left(-20^{\circ} \mathrm{C}\right.$ to $20^{\circ} \mathrm{C}$ ) experienced by the birds in the respirometric chamber more than covered the range of ambient temperatures experienced by Black Grouse in their winter environment; we had, however, to discount any potential radiative and convective effects, which would have singularly complicated modeling. The magnitude of these avenues of heat exchange is presently unknown for the Black Grouse in its natural habitat. In particular, convective heat loss probably accounts for only a negligible part of the total heat loss for birds resting in snow burrows, but it may represent a significant part of it for birds staying outside their igloo in windy conditions (e.g., compare to Ruffed Grouse, Bonasa umbellus [Thompson and Fritzell 1988]). Our estimates must therefore be seen as an approximation of the energy expenditure actually encountered by the birds in reality. Three captive-born Black Grouse cocks, of certified Alpine origin, were obtained from a zoological garden (Bern Tierpark) and transferred into outdoor aviaries of the University of Bern (Hasli ethological station). Birds were kept in captivity under license of the cantonal veterinary service (Bern). The measurements were restricted to January-March. The birds were fed a specific winter grouse diet (Protector SA, CH-1522
Lucens, Switzerland), and weighed on average $1030 \pm$ $22 \mathrm{~g}$ (mean $\pm \mathrm{SD})$.

Rate of metabolism.- In order to measure their rate of metabolism, these captive birds were transferred to the University of Lausanne, where they were kept in a semioutdoor enclosure for a maximum of three consecutive weeks. For Black Grouse we technically adapted the testing method outlined in Arlettaz et al. (2000) and Giorgi et al. (2001). Rate of oxygen consumption $\left(\mathrm{VO}_{2}\right)$ was measured at seven different ambient temperatures $\left(-20^{\circ},-10^{\circ},-5^{\circ}, 0^{\circ}, 5^{\circ}, 10^{\circ}\right.$, and $\left.20^{\circ} \mathrm{C}\right)$ in a plexiglass $(1-$ $\mathrm{cm}$ thick walls) metabolic chamber $(40 \times 40 \times 40 \mathrm{~cm})$, which was placed in a thermo-regulated climatizer (Weiss Technik AG, Kirchberg, Switzerland). Experiments were conducted during the daytime and lasted 4-5 h. While in the chamber, birds stayed in total darkness, but their behavior was monitored continuously using infrared video equipment. They were exposed to a constant airflow at $124 \mathrm{~L} / \mathrm{h} \mathrm{STPD}$ down to $-5^{\circ} \mathrm{C}$. Below $-5^{\circ} \mathrm{C}$, airflow had to be increased to $149 \mathrm{~L} / \mathrm{h}$, due to a higher metabolic rate, so as to maintain oxygen concentration in the chamber above $20 \%$. Upstream of the chamber, water vapor was removed by silica gel in order to avoid condensation within the chamber or freezing of tubes when working at temperatures below $0^{\circ} \mathrm{C}$. Downstream of the chamber, before entering the mass flowmeter, $\mathrm{CO}_{2}$ and water vapor were removed by potassium hydroxyde and silica gel, respectively. Airflow was controlled continuously by a calibrated mass flow meter (5850 E, Brooks Instruments, Veenendaal, The Netherlands) connected to control and read-out equipment (5878 E, Brooks Instruments). Oxygen concentration was measured continuously using an oxygen analyzer (Gas Purity Analyser Xentra 4100, Servomex, Esslingen, Switzerland) and data acquisition was performed by the Biobench program (National Instru- 
ments, Austin, Texas, USA). Rate of oxygen consumption (in milliliters of oxygen per hour) was calculated (Depocas and Hart 1957, Lighton 2008) as

$$
\mathrm{VO}_{2}=V_{2}\left(\mathrm{~F}_{1} \mathrm{O}_{2}-\mathrm{F}_{2} \mathrm{O}_{2}\right) /\left(1-\mathrm{F}_{1} \mathrm{O}_{2}\right),
$$

where $V_{2}$ is the measured flow rate (in milliliters per hour), $\mathrm{F}_{1} \mathrm{O}_{2}$ is the fraction of oxygen in the air entering the chamber (baseline before and after the experiment), and $\mathrm{F}_{2} \mathrm{O}_{2}$ is the fraction of oxygen in the air leaving the chamber during the experiment. For each run, a period of stable and minimal oxygen consumption corresponding to a fully resting bird was selected. Body mass was measured after the experiments, and for each bird and temperature level the mass-specific oxygen consumption rate (milliters of oxygen per gram per hour) was calculated. A conversion factor of $19.8 \mathrm{~J} / \mathrm{mL} \mathrm{O} \mathrm{O}_{2}$ was used to calculate the rate of metabolism (Lindström and Kvist 1995, Svensson et al. 1998).

Ambient, snow, and igloo temperature.-During and around the period of flushing experiments, ambient temperature ( $T_{\mathrm{a}}$, at $2 \mathrm{~m}$ above the snow surface, in the shade) and snow temperature $\left(T_{\mathrm{s}}\right.$, measured within snow $\sim 15 \mathrm{~cm}$ below the snow surface, i.e., approximately at snow burrow depth) were recorded every $10 \mathrm{~min}$ (Squirrel Meter, Typ 1006, Eltec, Haslingfeld, Cambridge, UK) in the vicinity of the bird. In order to account for the temperature differential within the igloo due to the birds' metabolic heat production, we equipped one cock with a tail-mounted thermo-sensitive tag (Holohil Systems Limited, Carp, Ontario, Canada) so as to collect data on the actual temperature within an igloo ( $T_{\mathrm{i}}$, for igloo temperature) when a bird was present. This enabled us to reconstruct the relationships between $T_{\mathrm{i}}, T_{\mathrm{s}}$, and $T_{\mathrm{a}}$. Signals from the transmitter were converted into temperature data using the calibration curve provided by the manufacturer and validated by ourselves under controlled thermal conditions.

Modeling extra energy expenditure induced by human disturbance.-Using our measurements of metabolic rate obtained from captive resting birds and our field activity budgets, we constructed a graphical model of the overall daily energy expenditure of birds of a similar body mass subjected to different $T_{\mathrm{a}}$ levels, for both the disturbed and undisturbed situations. The model aimed at visualizing the extra energy expenditure induced by human disturbance. It included additional costs induced by the escape flight in disturbed birds, the extra (if any) foraging time as well as the increased exposure to cold. We derived $T_{\mathrm{i}}$ for a defined air temperature through a two-step procedure: firstly by calculating the function linking $T_{\mathrm{s}}$ with $T_{\mathrm{a}}$, and, secondly, by linking $T_{\mathrm{i}}$ with $T_{\mathrm{s}}$. Daily mean durations of foraging during the pre-flushing baseline phase and during the experimental flushing phase were used to model energy expenditure in undisturbed vs. disturbed birds. However, as actual metabolic rates of foraging birds were not available, we estimated them by adding to the resting rate at the corresponding $T_{\mathrm{a}}$ a metabolic increment based on measurements made on the smaller (721.5 g) Ptarmigan, Lagopus muta (Lees et al. 2010). To calculate this increment, we assumed (1) that it would be similar in wintering Black Grouse and Ptarmigan (which is extremely conservative given that Black Grouse are larger), and (2) that the metabolic increment due to activity is independent of ambient temperature (the values for the wintering Ptarmigan were established for a $T_{\mathrm{a}}$ of $13.2^{\circ} \mathrm{C}$ ). We obtained a metabolic increment for activity of $19.1 \mathrm{~kJ} / \mathrm{h}$ at an assumed speed of $0.01 \mathrm{~m} / \mathrm{s}$, corresponding to a realistic average walking distance of $36 \mathrm{~m}$ an hour in a feeding Black Grouse. The extra energy expenditure caused by the escape flight itself was accounted for by using the equation of Tucker (1973; as rewritten by Peters 1983). For that purpose, we assumed a flight speed of $10 \mathrm{~m} / \mathrm{s}$ and used our average value of metabolic rate at $20^{\circ} \mathrm{C}$ as an estimate of basal metabolic rate (see Appendix: Fig. A2 for an explanation). Unfortunately, Tucker's equation does not include a possible thermal dependence of flight metabolism and was based on only a few species. Thus the value of metabolic rate during flight, which we calculated to be $38.7 \mathrm{~kJ} / \mathrm{h}$, should at best be considered indicative. However, this should be realistic enough, owing to the very short duration of such escape flights (we assumed a flight duration of $20 \mathrm{~s}$ ). Furthermore, disturbed birds would face additional energetic costs if denied the protective temperature buffer offered by an igloo, e.g., if they rested on trees after flushing, until the following foraging period. Therefore, we modeled different reactions to flushing, including variable durations $(0,1,2,5$, and $10 \mathrm{~h})$ of additional rest outside an igloo.

\section{Results}

\section{Stress hormone metabolites}

We found a significant seasonal effect on the concentration of fecal corticosterone metabolites (FCM; Fig. 3, likelihood ratio test: $\chi^{2}=8.95, \mathrm{df}=2, P$ $<0.05$ ), but no effect of the experimental treatment (flushing) on FCM concentration (likelihood ratio test: $\left.\chi^{2}=0.17, \mathrm{df}=2, P=0.9\right)$. The variation in individual stress response trajectories over the whole experiment (as estimated from the random effects of the mixed model) shows a clear funneling effect, as predicted by the allostatic theory (Fig. 4A and B). Whether a given individual increased or decreased its FCM levels between pre-flushing conditions and the experimental flushing treatment depended on its initial FCM concentration (Figs. 4A and 5A). This means that birds with high levels of stress hormone during pre-flushing decreased FCM concentrations, while individuals with relatively low initial baseline FCM concentrations increased their FCM excretion (linear regression: $R^{2}=$ 0.73, $F_{1,10}=27.18, P<0.001$; Fig. 5A). Based on this linear regression, an allostatic overload would be attained in our Black Grouse when the baseline (preflushing) stress hormone level reached a median of 66.2 


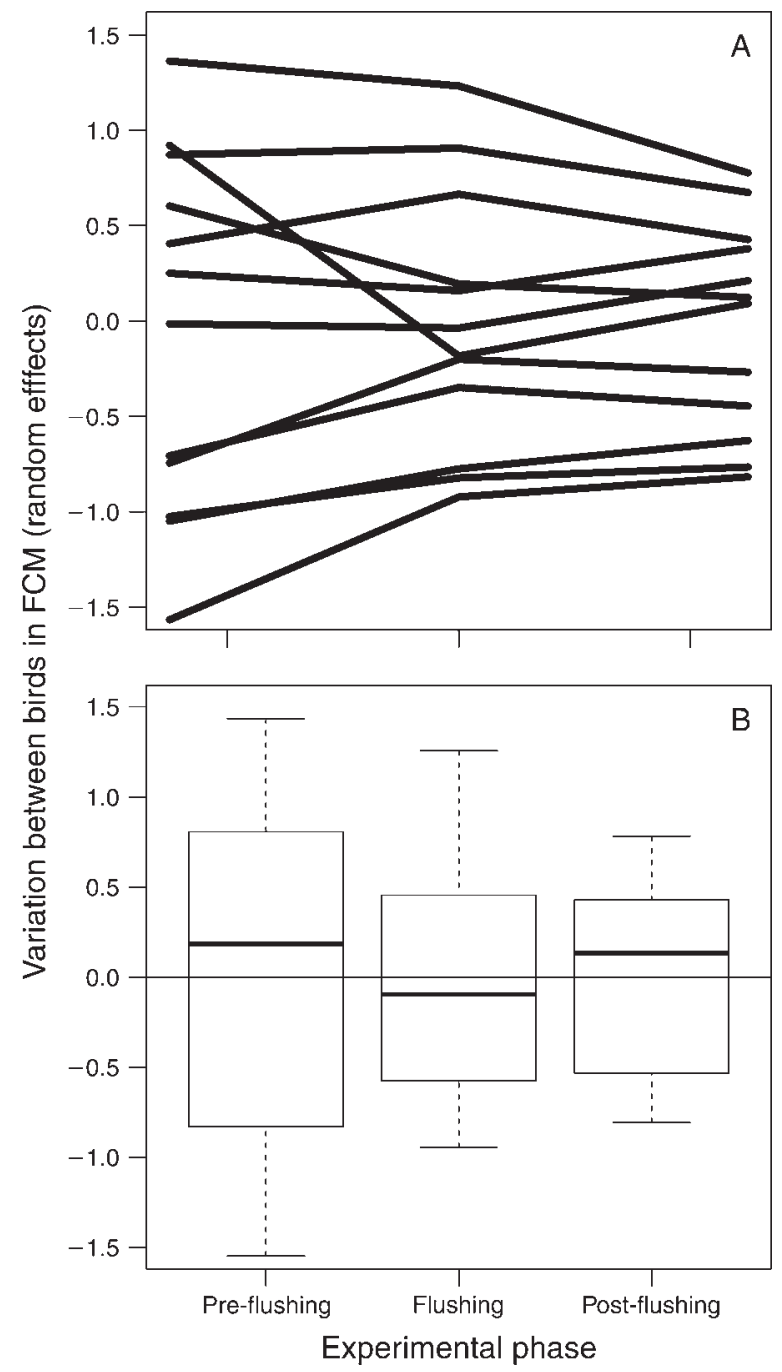

FIG. 4. Random effects of the mixed model (including time and treatment as fixed effects and bird identity as random effect) with respect to the experimental phase: pre-flushing (baseline), experimental flushing treatment, post-flushing. (A) Each trajectory represents the relative stress response of an individual $(n=$ 12) compared to the stress level expected at a given date (i.e., accounting for seasonal effect). (B) The same data summarized as Tukey boxplots (bold horizontal lines, medians; upper and lower box boundaries, first and last quartiles; dashed vertical lines, inter-quartile distance multiplied by 1.5 ). The funneling effect predicted by the allostatic theory of stress is clearly recognizable. Detailed information about sample sizes is found in Material and methods: Stress response.

$\mathrm{ng} / \mathrm{g}$ (interquartile range: $53.3-80.1 \mathrm{ng} / \mathrm{g}$, which corresponds to $3.98-4.38$ on the log-transformed $x$-axis in Fig. 5A). In fact, above this value, an average bird within our study is predicted to decrease its FCM excretion when flushed (Fig. 5A), which, within the framework of the allostatic theory, would occur in a situation of allostatic overload. Permutation tests indicated a decreased variance in FCM values throughout the experiment: the variance was 1.8 times greater during the pre-flushing phase than during the experi- mental flushing treatment (Fig. 4B, $n=10000$ permutations, $P=0.003$ ), as predicted. However, the variance was also 2.8 times greater during the pre-flushing phase than during the post-flushing phase $(n=10000$

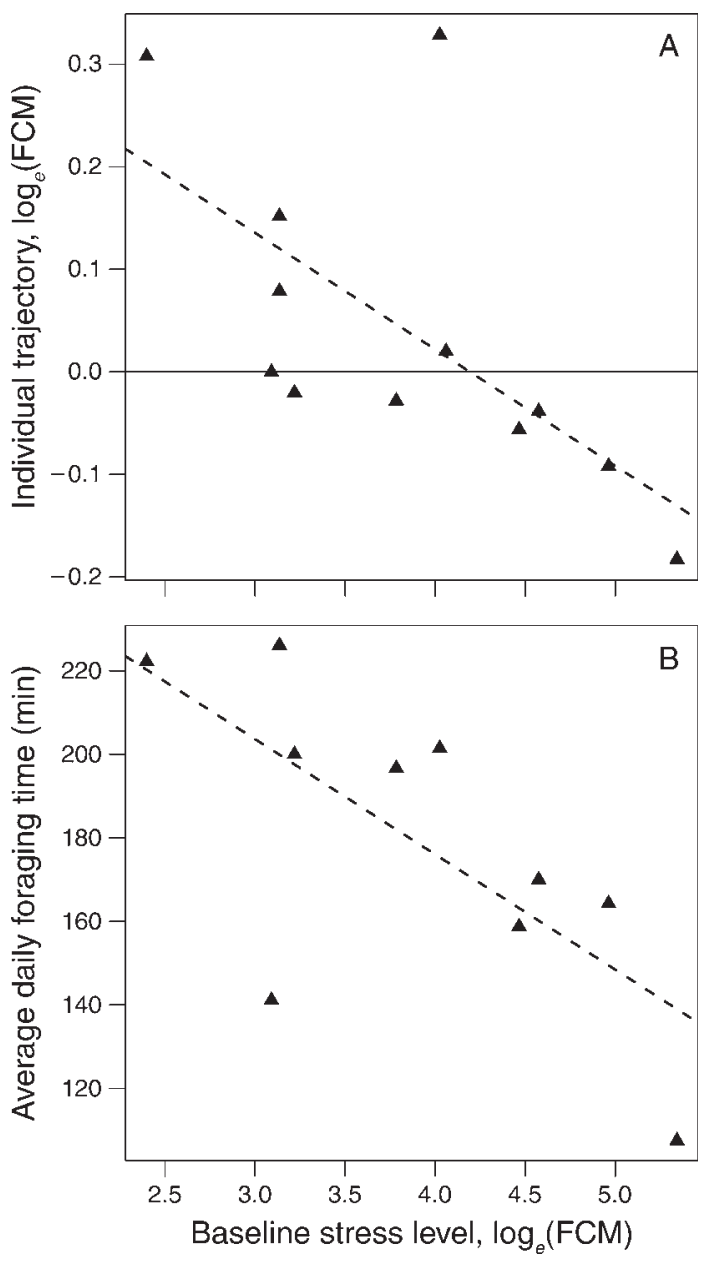

FIG. 5. (A) Individual trajectories in FCM (fecal corticosterone metabolites) concentrations (originally measured as nanograms per gram per day) over the three experimental phases expressed as a function of initial baseline FCM values (both $\log _{e}$-transformed). The trajectory is the slope of the linear regression of $\log _{e}$-transformed FCM concentration as a function of the number of days following initial disturbance, i.e., for each bird it quantifies the average individual daily change in FCM concentration. The baseline stress level corresponds to the $\log _{\mathrm{e}}$-transformed FCM concentration in the pre-flushing phase. The point where the regression line between individual trajectory and baseline crosses 0 (at 4.19 $\log _{e}$-transformed FCM, i.e., $66.2 \mathrm{ng} / \mathrm{g}$ ) would correspond to the limit between allostatic load and overload, i.e., when the organism enters an ELHS (see Fig. 1). (B) Individual foraging activity averaged across the three experimental phases expressed as a function of initial baseline FCM concentration ( $\log _{e}$-transformed). In brief: individuals with high initial baseline, pre-flushing FCM concentrations not only lowered their FCM excretion during the experimental flushing treatment, but they also performed relatively short foraging bouts, while individuals with low initial baseline values not only increased their FCM stress response but also performed relatively long foraging bouts. 
TABLE 1. Effect of repeated experimental flushings on early morning (a.m.) and evening (p.m.) foraging duration (mean $\pm \mathrm{SE})$ in 11 radio-tagged Black Grouse cocks in the Swiss Alps obtained with mixed-effects modeling.

\begin{tabular}{lcr}
\hline \hline & \multicolumn{2}{c}{ Foraging time (min) } \\
\cline { 2 - 3 } Experimental phase & \multicolumn{1}{c}{ a.m. } & \multicolumn{1}{c}{ p.m. } \\
\hline Pre-flushing baseline & $89.5 \pm 7.5$ & $91.3 \pm 9.5$ \\
Experimental flushing & $82.8 \pm 6.4$ & $112.0 \pm 8.3$ \\
Post-flushing & $83.4 \pm 7.7$ & $71.1 \pm 9.9$ \\
\hline
\end{tabular}

Note: The experimental design is described in Fig. 2.

permutations, $P<0.001$, and 1.6 times greater during the experimental flushing phase than during the postflushing ( $n=10000$ permutations, $P=0.005)$, which contradicts our prediction of a progressive return to preflushing baseline variation a few days after disturbance has ceased. This pattern suggests that the funneling effect lasted longer than initially expected when we designed the experiment, i.e., that there was some distinct stress state retention in the short-mid term.

\section{Foraging activity}

A clear bimodal daily activity pattern was recognized for each of the 11 Black Grouse males that yielded sufficient data (see Appendix: Fig. A1). The effect of repeated experimental flushings on early morning (a.m.) and evening (p.m.) foraging duration (minutes) are shown in Table 1. We found that the duration of the morning foraging bout (based on true foraging time) did not differ significantly between the three phases of the experiment (pre-flushing, experimental flushing treatment, and post-flushing) (likelihood ratio test: $\mathrm{df}=2, \chi^{2}$ $=0.70, P=0.7)$. However, the evening foraging activity (based on residuals as we accounted for a seasonal effect, see Material and methods) significantly differed between the experimental phases (likelihood-ratio test: $\left.\mathrm{df}=2, \chi^{2}=14, P<0.001\right)$. Accordingly, post hoc contrast tests showed that the foraging duration did not differ between any pair of the experimental phases with regard to morning foraging bouts, but such pairwise differences were apparent for evening foraging bouts (again based on residuals). There was a marginally significant increase between pre-flushing and flushing values of $17.0 \pm 10.4$ residual minutes per day (mean \pm $\mathrm{SE}$; linear mixed model, MCMC samples $=10000$, $\left.P_{\text {MCMC }}<0.10\right)$. We also found a significant decrease in foraging time of $-24.6 \pm 11.5$ residual minutes per day between the pre-flushing and post-flushing phases (linear mixed model, MCMC samples $=10000, P_{\text {MCMC }}<$ 0.05 ), and also a significant decrease of $-42.3 \pm 11.5$ residual minutes per day between flushing and postflushing phases (linear mixed model, MCMC samples = $\left.10000, P_{\mathrm{MCMC}}<0.001\right)$ (Fig. 6).

Notwithstanding seasonal effects due to the short duration of our individual experiments $(<8$ days for 11 individuals, and only 1 individual that had its preflushing control measure taken much earlier than the treatment phase), the mean evening individual foraging duration increased from 91 to $112 \mathrm{~min}$ between preflushing and flushing conditions. This would mean that anthropogenic disturbance provokes an average increase of $23 \%$ of the time devoted to foraging in the evening (Fig. 6). When accounting for the potential bias linked to seasonal effects, comparison of residuals of the regression between evening foraging activity and the Julian date in the different phases, referring to an average evening foraging duration of $95.8 \mathrm{~min}$ across the whole experiment, we obtained an average increased residual evening foraging duration of $17 \mathrm{~min}(18 \%)$ between the pre-flushing phase and the flushing phase (not illustrated, as similar to Fig. 6). Note that this prolongation of evening foraging bouts cannot be due to an opportunistic anticipation of foraging following flushing: there was in fact no difference in the starting time of activity between control and treatment days. According to our field surveys, once disturbed, birds either dug a new igloo or rested on trees until just before dusk when foraging started.

Finally, we observed a significant negative relationship between individual daily foraging duration (averaged across all experimental phases) vs. pre-flushing baseline stress response (linear regression: $F_{1,8}=7.56, P$ $=0.026)$ and the individual stress trajectory (slope) (linear regression: $F_{1,8}=7.95, P=0.022$ ). However, when considering morning and evening foraging separately, only the duration of the evening foraging bout

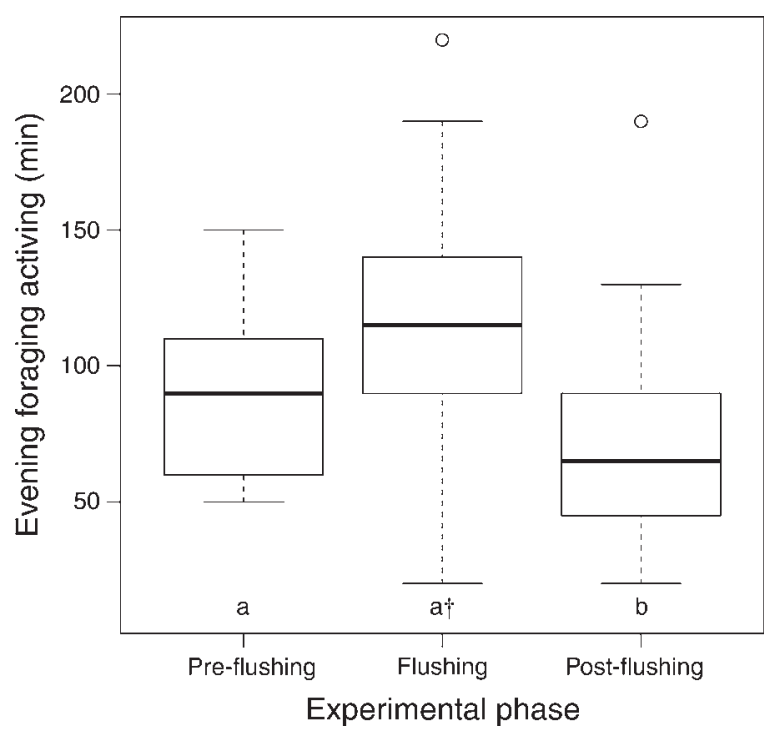

FIG. 6. Evening foraging duration (minutes) of Black Grouse as a function of the experimental phase. Tukey boxplots (bold horizontal lines, medians; upper and lower box boundaries, first and last quartiles; dashed vertical lines, inter-quartile distance multiplied by 1.5 ; circles, extreme values situated outside inter-quartile distance multiplied by 1.5). The outcome of post hoc tests on residuals (see Table 1 and text for more detail) is shown with letters, different letters indicating significant differences, $P<0.05$ (or marginally significant difference in the case of the dagger). 

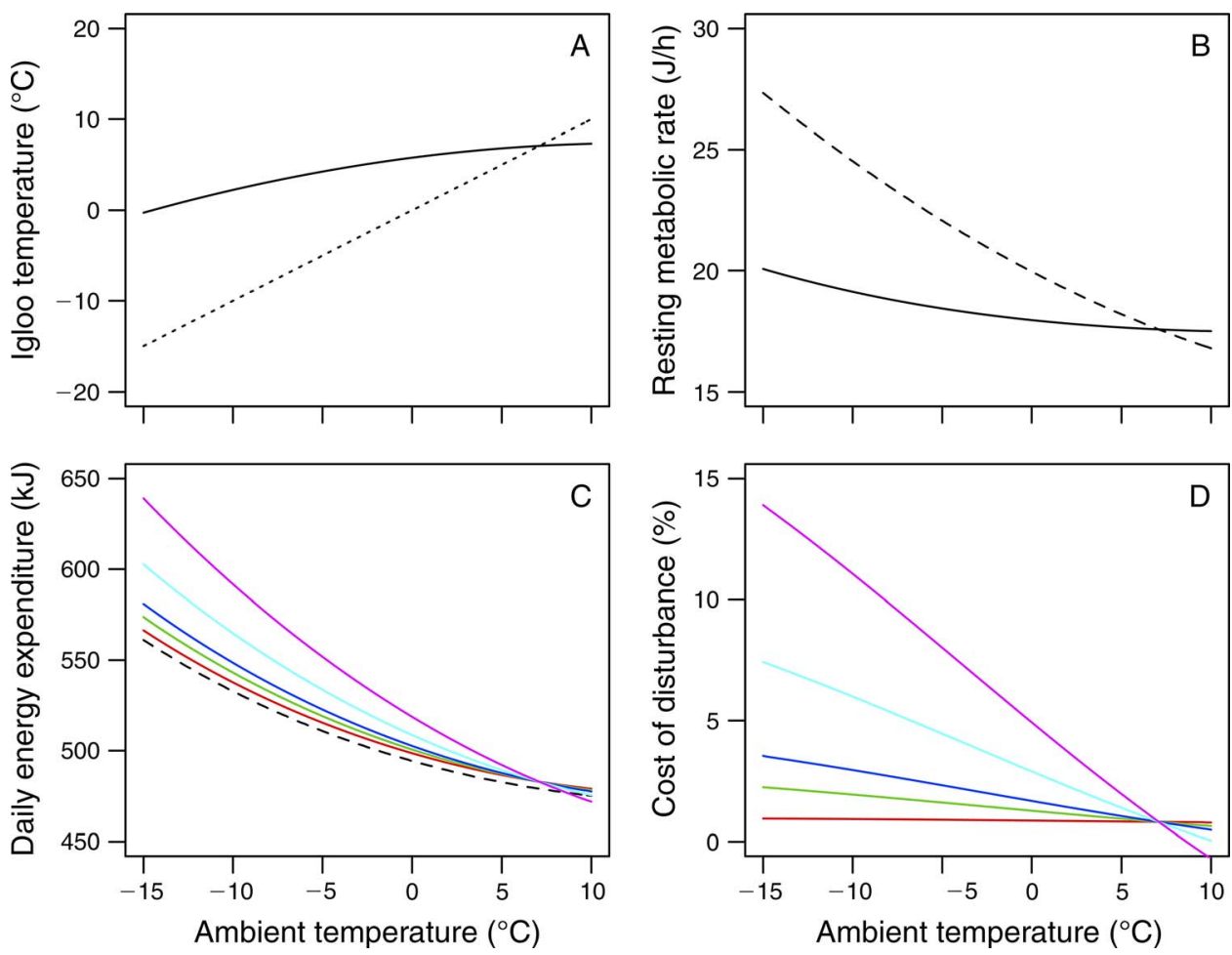

FIG. 7. (A) Igloo temperature ( $T_{\mathrm{i}}$, solid line, measured via bird radiotelemetry) as a function of ambient temperature ( $\left.T_{\mathrm{a}}\right)$ providing an estimation of the thermal buffer of snow burrows. The dotted line depicts equality between $T_{\mathrm{i}}$ and $T_{\mathrm{a}}$. (B) Projection of the related mass-specific resting rate of metabolism (in joules per hour) with respect to ambient temperature, which provides an estimate of the energy gains obtained by birds resting in igloos. The dashed curve is for an unsheltered bird and the solid curve for a bird resting in an igloo. (C) Estimated daily energy expenditure for undisturbed birds (dashed curve) and flushed birds returning to a new shelter after $0 \mathrm{~h}$ (red curve), $1 \mathrm{~h}$ (green), $2 \mathrm{~h}$ (dark blue), $5 \mathrm{~h}$ (light blue), and $10 \mathrm{~h}$ (purple). (D) Estimated cost of flushing expressed as a percentage of the daily energy expenditure of an undisturbed bird (same colors as graph $\mathrm{C}$ ).

showed significant correlations with the two stress measures (linear regressions, baseline stress response: $F_{1,8}=5.46, P=0.048$, Fig. 5B; individual trajectory, $F_{1,8}$ $=7.02, P=0.029$ ).

\section{Energetics}

Rate of metabolism.-The captive cocks responded to a decrease of ambient temperature $\left(T_{\mathrm{a}}\right)$ by increasing their rate of oxygen consumption. Between $-20^{\circ} \mathrm{C}$ and $20^{\circ} \mathrm{C}$, this relationship is best described by a quadratic function, $\mathrm{VO}_{2}=0.97860-0.01898 T_{\mathrm{a}}+0.00034 T_{\mathrm{a}}^{2}$, where $\mathrm{VO}_{2}$ is expressed in milliliters of oxygen per gram per hour (see Appendix: Fig. A2 for more details).

Snow, igloo, and daily mean ambient temperatures.The relationship between mean daily snow temperature at igloo depth $\left(T_{\mathrm{s}}\right)$ and mean daily $\mathrm{T}_{\mathrm{a}}$ fits a polynomial model: $T_{\mathrm{s}}=-1.648+0.185 T_{\mathrm{a}}-0.012\left(T_{\mathrm{a}}-4.988\right)^{2}\left(R^{2}=\right.$ $0.7743, P<0.0001)$. There was a linear relationship between mean hourly igloo temperature $\left(T_{\mathrm{i}}\right.$, estimated from a tail-mounted radio transmitter) and mean hourly $T_{\mathrm{s}}: T_{\mathrm{i}}=7.4184+0.8359 T_{\mathrm{s}}\left(R^{2}=0.3378, P<0.0001\right)$. On the basis of the two preceding equations, igloo temperature was higher than ambient temperature below a $T_{\mathrm{a}}$ of $7^{\circ} \mathrm{C}$ (Fig. 7A).
Modeling energy budgets.-Due to the buffering effect of the igloo, the resting rate of metabolism of sheltered birds was predicted to be lower than that of unsheltered birds below $7^{\circ} \mathrm{C}$ (Fig. 7B), the difference increasing with decreasing $T_{\mathrm{a}}$. At $-15^{\circ} \mathrm{C}$, energy saving exceeded $25 \%$ (Fig. 7B). The predicted daily energy expenditure of undisturbed birds (mean body mass of $1.03 \mathrm{~kg}$ ) increased with decreasing $T_{\mathrm{a}}$ from $475 \mathrm{~kJ} / \mathrm{d}$ at $10^{\circ} \mathrm{C}$ to $561 \mathrm{~kJ} / \mathrm{d}$ at $-15^{\circ} \mathrm{C}$ (Fig. $7 \mathrm{C}$, dashed curve). Predicted energy expenditure of disturbed birds increased with decreasing $T_{\mathrm{a}}$ as well, but was higher than that of undisturbed birds below $7^{\circ} \mathrm{C}$ and strongly depended on the duration of the additional rest spent outside an igloo following disturbance (Fig. 7C and D). In the case of a disturbed bird returning immediately to a new igloo after disturbance, the cost of flushing ranged between $0.8 \%$ and $0.9 \%$ of the overall daily energy expenditure of an undisturbed bird (Fig. 7D, red curve). However, this cost increased strongly with an increase in the time spent outside an igloo after disturbance, reaching almost $15 \%$ in birds that rested unsheltered for $10 \mathrm{~h}$ at a $T_{\mathrm{a}}$ of $-15^{\circ} \mathrm{C}$ (Fig. 7D, purple curve). This could occur in a bird disturbed in the morning and delaying a return to an igloo until after the evening foraging bout. In such a case, our model predicts a daily energy expenditure 
exceeding $600 \mathrm{~kJ} / \mathrm{d}$ at low $T_{\mathrm{a}}$ (Fig. 7C). The escape flight following a disturbance $(\sim 0.2 \mathrm{~kJ}$, or $<0.05 \%$ of the daily energy expenditure of an undisturbed bird), as well as the additional time spent foraging $(0.8-0.9 \%)$, induced only marginal additional energy costs in the modeled conditions.

\section{DisCUSSION}

There has been a reiterated call (e.g., Carey 2005, Stevenson 2006, Homyack 2010, Ellis et al. 2012) to perform more integrated research in the field of conservation physiology. By simultaneously measuring glucocorticoid excretion, activity, and energy budgets, the present experiments contribute to bridging this gap. This study confirms that outdoor winter recreation (by back-country skiers, snowboarders, and snowshoers) has an impact on wildlife (for Black Grouse, see Arlettaz et al. 2007, Patthey et al. 2008, Braunisch et al. 2011), provoking subtle allostatic, physiological adjustments and behavioral responses. To our knowledge, and for the first time, it demonstrates the existence of a funneling effect, as predicted by the allostatic theory of stress, with a non-unidirectional individual stress response to disturbance. We observed that FCM is modulated by initial stress level. Individuals with a low initial concentration of stress hormone metabolites (FCM) increased their stress response during experimental flushing, while individuals with high initial values lowered their response. According to the allostatic theory of stress, the latter individuals should thus have experienced an allostatic overload, which might have led to an emergency life history stage (ELHS; McEwen and Wingfield 2003), with an obligatory drop in stress hormone excretion so as to return to homeostasis. Similar physiological response patterns have been observed in arctic birds exposed to severe weather conditions during breeding (Wingfield et al. 1997), but apparently not until now in wildlife exposed to anthropogenic disturbance. An FCM concentration of $50-80 \mathrm{ng} / \mathrm{g}$ FCM might be roughly indicative of the allostatic load-overload threshold in Black Grouse. Even so, this absolute figure must be treated with caution because different laboratories typically deliver different estimates of FCM concentration, due to discrepancies in the standardization of settings and procedures (Romero 2004, Palme et al. 2013).

A previous comparative analysis at a broader scale established that stress levels in Black Grouse do not differ between Alpine ski resorts (high level of disturbance, typically due to on-piste and off-piste skiing) and more natural areas but subjected to frequent human disturbance (moderate disturbance, mostly by backcountry skiing and snowshoeing), while birds in these two environments showed significantly higher FCM concentrations than in natural areas with null disturbance (Arlettaz et al. 2007). In the light of both the allostatic theory (which implies a funneling effect instead of a cumulative linear response) and present results, we can reinterpret the FCM pattern previously observed in Black Grouse across sites with different levels of human disturbance (Arlettaz et al. 2007). Since the stress response of birds in heavily disturbed habitats is not significantly higher than in moderately disturbed habitats (Arlettaz et al. 2007), birds in heavily disturbed habitats might actually be experiencing recurrent EHLS, which would hamper a further mounting of their stress response. We thus posit that individuals close to ski resorts, where anthropogenic disturbance is highest, might actually face a situation of chronic stress (Hofer and East 1998, Cyr et al. 2007, Cyr and Romero 2009) with possible impacts on survival and, therefore, population dynamics. This could explain why ski resorts harbor lower population densities of Black Grouse than natural areas (Patthey et al. 2008).

Our field experiment also suggests that repeated disturbance, i.e., daily flushing of the radio-monitored birds in the early afternoon, provoked a prolongation of the time devoted to foraging. Such a compensatory mechanism has been described earlier in birds and mammals (Bélanger and Bédard 1990, Gutzwiller et al. 1998, Frid and Dill 2002, Fortin and Andruskiw 2003, Reimers et al. 2003, Taylor and Knight 2003). The observation that birds rapidly replenish energetic reserves following disturbance may reflect the fact that Black Grouse cannot rely on much fat reserves during winter but have to mobilize muscle proteins (proteins cannot be stored like fat) if they require a sudden extra source of energy (Willebrand and Marcström 1989). Another new finding emerging from this study lies in the observation that birds with elevated FCM concentration after flushing (typically the individuals with low initial pre-flushing baseline FCM values that showed steep FCM uptrajectories after experimental flushing) foraged more, on average (i.e., across all experimental phases), than birds that had diminished their FCM concentrations after flushing, and vice versa. This provides further support to our interpretation that birds with high initial FCM concentrations were not only experiencing a situation of allostatic overload but possibly even facing an ELHS.

Our finding that dusk foraging bout duration was affected by experimental flushing while morning foraging duration was not, also suggests that diurnal variance in stressors probably have complex interactions with the foraging ecology of Black Grouse. The pressure exerted by the first arriving skiers might have played a role, as established by Arlettaz et al. (2013). In effect, birds are often forced to retreat early, i.e., prior to having filled their crop in the morning, whereas more time for feeding might be available at dusk after all skiers have left the pistes in the late afternoon (Arlettaz et al. 2013). The evening foraging bout duration was also significantly shorter during post-flushing than pre-flushing and flushing. We would have predicted that post-flushing foraging would return to pre-flushing levels, but the unexpected retention of stress we observed until the end of the experiment leads us to predict, a posteriori, that 

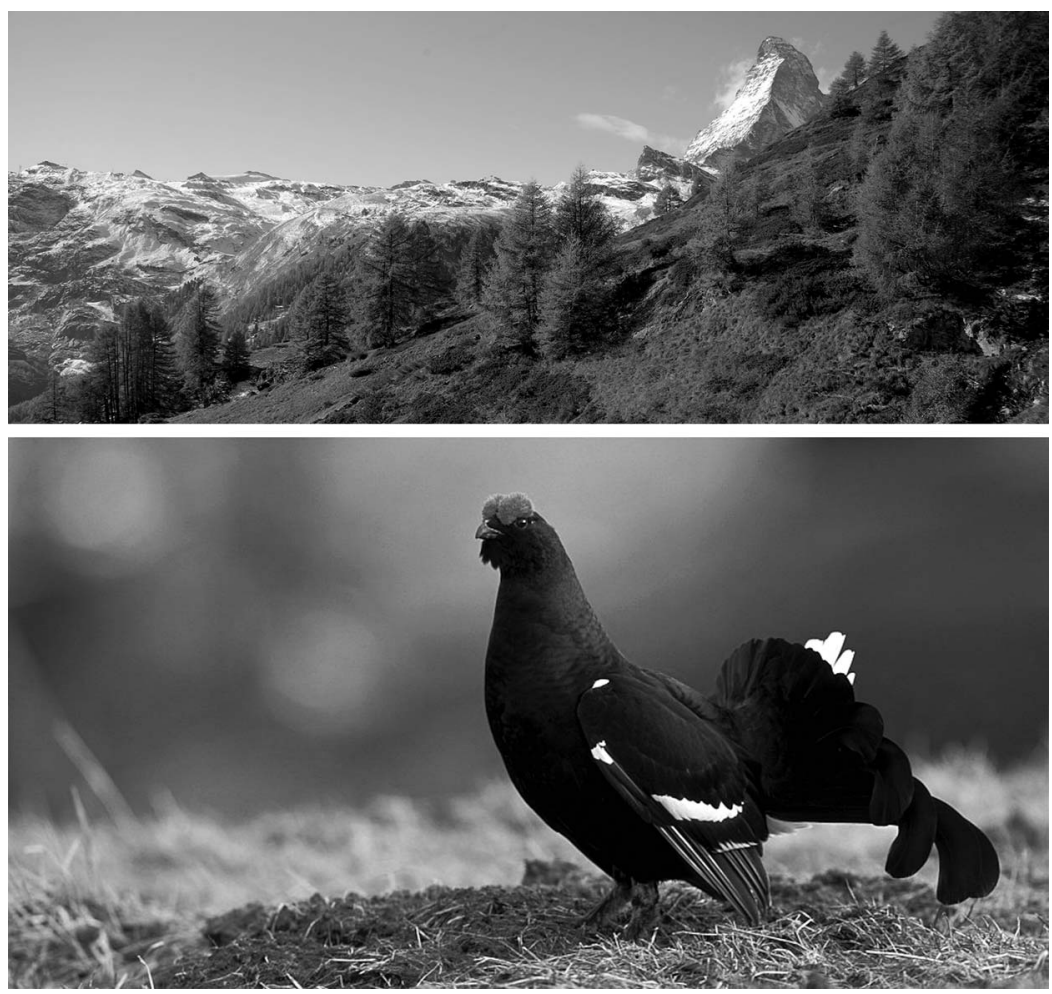

Plate 1. (Above) In the European Alps, (below) Black Grouse (here a male) inhabit timberline habitats where the majority of outdoor snow-sport activities take place. Photo credits: Matterhorn, Zermatt, Valais, southwestern Switzerland by R. Arlettaz; Black Grouse by P. Patthey.

foraging should be comparable during the flushing and post-flushing phases. The reason for this discrepancy might be the spatial shift we observed in several birds between the continuous period with daily flushings and the post-flushing phase that followed the interruption of the experiment during several days (Fig. 2), which impeded collecting post-flushing samples from four birds due to translocation to remote, avalanche-prone areas (see Material and methods: Stress response). The pressure exerted upon birds by our daily successive flushings (up to four in a row) might have forced these to quit their traditional winter grounds for areas providing both less anthropogenic disturbance and sufficient food supply, i.e., "quicker" foraging opportunities overall. Whatever the reasons for this unexpected pattern, we conclude that even when disturbance of a bird occurs only once a day, a common disturbance frequency in areas regularly visited by snow-sports participants in the European Alps, it negatively affects the winter activity of Black Grouse, prompting rapid energy restoration.

Our energetic model indicates that prolonged exposure to low winter ambient temperature after disturbance, instead of benefiting from the igloo temperature buffer (Marjakangas 1986), might be the principal reason for this extra food intake. This model was based on estimations of oxygen consumption obtained from laboratory birds. The figures we obtained differed from the data collected in Finland (Oulu, $65^{\circ} \mathrm{N}$ ) by Rintamäki et al. (1983). The shape of the respective oxygen consumption curves looked similar, without a distinct inflection point indicating the lower limit of the thermoneutral zone, even if the Finnish data (Rintamäki et al. 1983) do suggest that the highest experimental temperature to which we exposed our birds $\left(20^{\circ} \mathrm{C}\right)$ lies close to, or within, thermal neutrality. Yet within the entire range of experimental temperatures, rates of oxygen consumption of the Scandinavian Black Grouse were much higher than those of our Alpine birds (amounting to $170 \%-199 \%$ of our values between $-20^{\circ} \mathrm{C}$ and $5^{\circ} \mathrm{C}$ ). This discrepancy can have several causes. The geographical origin of the birds may be a first explanation. On the one hand, Weathers (1979) calculated that among species of birds, the metabolic rate increases on average by $1 \%$ of the value predicted on the basis of body mass per degree in latitude (whereby the mid-latitude of the species' range was considered). While the latter relationship is an interspecific one, a similar variation in the rate of metabolism might also be hypothesized among geographically distant populations of the same species. On the other hand, our experimental birds were lent by the Bern Zoo (500 m altitude) and were therefore acclimatized to a lowland environment differing from their upland habitat. This acclimatization to low elevation could slightly affect the level and shape of the curves predicting the resting metabolic rate at different ambient temperatures (Fig. 7B; e.g., McKechnie 2008 for basal 
metabolic rate), but should not change our general conclusions about the magnitude of the costs of disturbance (Fig. 7D). A second major source of bias could be methodological. The birds measured by Rintamäki et al. (1983) were captured in the field and kept for only 1-2 days in captivity before being measured; they also had a cloacal temperature probe and three needle electrodes penetrating the pectoral muscle during the measurements. This experimental procedure might have added stress and led to higher rates of metabolism. Unfortunately, direct measurement of energy expenditure, for instance by the doubly labelled water method, was not possible in the present study because recapture of free-ranging Black Grouse in the rough Alpine terrain is almost unfeasible and would in any case lead to additional stress incompatible with the type of experiments we conducted.

In our energetic model, extra time devoted to foraging after disturbance induced an increase of $0.8-0.9 \%$ of the overall daily energy expenditure of birds, while the cost of the escape flight itself was almost negligible $(0.05 \%$ at most). Much higher costs were incurred in birds delaying their return to an igloo until several hours after the disturbance, exceeding $10 \%$ of daily energy expenditure at a low ambient temperature for birds resting for several hours in unsheltered conditions. The latter case is in fact fairly realistic, as several of our disturbed birds rested on trees for relatively long time periods. Still, our estimates must be considered to be conservative. First, we had no measurements of the metabolic costs of foraging in our birds and had to extrapolate them on the basis of published data on the Rock Ptarmigan (Lees et al. 2010). By assuming a similar absolute incremental cost of being active in our larger species, we underestimated these costs. Second, our respirometric measurements were done in a chamber where the only air movements came from the flow of air provided to the birds. In more windy conditions, the resting metabolic rate at a particular $T_{\mathrm{a}}$ would be higher, which would further increase the difference between sheltered and unsheltered birds. Third, one disturbance event a day does not represent a worst-case scenario, since flushing may occur more frequently, even if not necessarily from a snow burrow, but from a tree perch, for example, especially close to ski resorts and in other heavily frequented mountain areas. This would further exacerbate the problems described above. Additional issues faced by disturbed birds include obstructed access to optimal foraging grounds (West et al. 2002) and induced starvation. It has been shown that the closely related Capercaillie (Tetrao urogallus), which, similarly to Black Grouse, has only limited fat deposits, can survive nine days of food deprivation (Hissa et al. 1990). Given that Capercaillie is the grouse species with the highest capacity to withstand starvation (Hissa et al. 1990), we can expect a higher susceptibility to starvation in the Black Grouse due to its lower body mass.
Finally, the extra time spent outside igloos, caused by prolonged evening foraging bouts after flushing disturbance, represented an additional exposure to predators, with Black Grouse being very conspicuous on a snow background. The situation would obviously be much worse in birds delaying their return to an igloo long after disturbance. This may be another serious additional risk if one considers that predation is the main cause of natural mortality in alpine Black Grouse populations (R. Arlettaz and P. Patthey, unpublished observations).

\section{Conclusion}

There is evidence that Black Grouse population density is much lower in ski resort areas compared to natural habitats, and that this results from anthropogenic factors linked to outdoor snow-sports activity rather than other factors such as hunting pressure or breeding habitat quality (Patthey et al. 2008). This has been further corroborated by spatially explicit modeling of Black Grouse population distribution between periods of pre- and post-development of ski infrastructure and/or outdoor snow-sports activity (Braunisch et al. 2011). This study provides further arguments that birds do face difficulties due to the development of snow-sports, justifying action to prevent further decline of the Alpine Black Grouse. The simplest and so far most efficient solution is to create winter refuges that limit to a minimum the interaction between snow-sports participants and Black Grouse, as demonstrated by the success story reported in Arlettaz et al. (2013: Fig. 7). What remains to be explained, however, are the subtle mechanisms at work. A new, promising avenue of research would be to quantify in parallel the effects of human disturbance upon individual physiological state and vital rates, namely survival and reproductive success. A demonstration of the demographic mechanisms involved would provide clear and comprehensive evidence of the existence of populations experiencing allostatic overload caused by anthropogenic winter disturbance.

\section{ACKNOWLEDGMENTS}

We thank H. Richner, who allowed us to use the aviaries of the Hasli ethological station, as well as O. Roth, who helped with captive birds. M. Giorgi, Lausanne, gave advice in the respirometry lab. The ski resorts of Verbier and Les Diablerets provided free accommodation and ski passes. S. Mettaz, T. Leu, T. Berger, G. Obrist, and C. Buchli assisted during field work, and D. Thiel with laboratory analyses. R. Alatalo and E. Möstl provided useful criticism about the manuscript. Aliki Buhayer corrected the English. This research was funded by a grant from the Swiss National Science Foundation to R. Arlettaz. We dedicate this article to the memory of our coauthor Professor Dr. Peter Vogel (5 February 1942-12 January 2015) in acknowledgment of his lifetime commitment to wildlife research and conservation.

\section{Literature Cited}

Arlettaz, R., P. Patthey, M. Baltic, T. Leu, M. Schaub, R. Palme, and S. Jenni-Eiermann. 2007. Spreading free-riding snow sports represent a novel serious threat for wildlife. Proceedings of the Royal Society B 274:1219-1224. 
Arlettaz, R., P. Patthey, and V. Braunisch. 2013. Impacts of outdoor winter recreation on alpine wildlife and mitigation approaches: a case study of the Black Grouse. Pages 137-154 in C. Rixen and A. Rolando, editors. The impacts of skiing and related winter recreational activities on mountain environments. Bentham eBooks, Bussum, The Netherlands.

Arlettaz, R., C. Ruchet, J. Aeschimann, E. Brun, M. Genoud, and P. Vogel. 2000. Physiological traits affecting the distribution and wintering strategy of the bat Tadarida teniotis. Ecology 81:1004-1014.

Baines, D., and M. Richardson. 2007. An experimental assessment of the potential effects of human disturbance on Black Grouse Tetrao tetrix in the North Pennines, England. Ibis 149:56-64.

Baltic, M., S. Jenni-Eiermann, R. Arlettaz, and R. Palme. 2005. A noninvasive technique to evaluate human-generated stress in the black grouse. Annals of the New York Academy of Sciences 1046:81-95.

Bates, D., M. Maechler, and B. Bolker. 2011. lme4: linear mixed-effects models using S4 classes. R package version 0.999375-42. http://CRAN.R-project.org/package=lme4

Bates, D. M. 2010. lme4: mixed-effects modeling with R. Springer, New York, New York, USA.

Bélanger, L., and J. Bédard. 1990. Energetic cost of maninduced disturbance to staging snow geese. Journal of Wildlife Management 54:36-41.

Bossert, A. 1980. Winterökologie des Alpenschneehuhns (Lagopus mutus Montin) im Aletschgebiet, Schweizer Alpen. Der Ornithologische Beobachter 77:121-166.

Braunisch, V., P. Patthey, and R. Arlettaz. 2011. Spatially explicit modelling of conflict zones between wildlife and outdoor snow-sports: prioritizing areas for winter refuges. Ecological Applications 21:955-967.

Brodin, A. 2001. Mass-dependent predation and metabolic expenditure in wintering birds: Is there a trade-off between different forms of predation? Animal Behaviour 62:993-999.

Busso, J., M. F. Dominchin, R. H. Marin, and R. Palme. 2013. Cloacal gland, endocrine testicular, and adrenocortical photoresponsiveness in male Japanese quail exposed to short days. Domestic Animal Endocrinology 44:151-156.

Careau, V., D. Thomas, M. Humphries, and D. Réale. 2008. Energy metabolism and animal personality. Oikos 117:641653.

Carey, C. 2005. How physiological methods and concepts can be useful in conservation biology. Integrative and Comparative Biology 45:4-11.

Cyr, N. E., K. Earle, C. Tam, and L. M. Romero. 2007. The effect of chronic physiological stress on corticosterone, plasma metabolites, and immune responsiveness in European starlings. General and Comparative Endocrinology 154:59-66.

Cyr, N. E., and L. M. Romero. 2009. Identifying hormonal habituation in field studies of stress. General and Comparative Endocrinology 161:295-303.

Depocas, F., and S. J. Hart. 1957. Use of the Pauling oxygen analyser for measurement of oxygen consumption of animals in open-circuit systems and in a short-lag, closed circuit apparatus. Journal of Applied Physiology 10:388-392.

Ellis, R. D., T. J. McWorther, and M. Maron. 2012. Integrating landscape ecology and conservation physiology. Landscape Ecology 27:1-12.

Fortin, D., and M. Andruskiw. 2003. Behavioral response of free-ranging bison to human disturbance. Wildlife Society Bulletin 31:804-813.

Fowler, G. S. 1999. Behavioral and hormonal responses of Magellanic penguins (Spheniscus magellanicus) to tourism and nest site visitation. Biological Conservation 90:143-149.

Frid, A., and L. Dill. 2002. Human-caused disturbance stimuli as a form of predation risk. Conservation Ecology 6:11. http://www.consecol.org/vol6/iss1/art11

Giorgi, M. S., R. Arlettaz, P. Christe, and P. Vogel. 2001. The energetic grooming costs imposed by a parasitic mite
(Spinturnix myoti) upon its bat host (Myotis myotis). Proceedings of the Royal Society B 268:2071-2075.

Goymann, W., E. Möstl, and E. Gwinner. 2002. Corticosterone metabolites can be measured noninvasively in excreta of European Stonechats (Saxicola torquata rubicola). Auk 119:1167-1173.

Gutzwiller, K. J., H. A. Marcum, H. B. Harvey, J. D. Roth, and S. H. Anderson. 1998. Bird tolerance to human intrusion in Wyoming montane forests. Condor 100:519-527.

Hissa, R., H. Rintamaki, P. Virtanen, H. Linden, and V. Vihko. 1990. Energy reserves of the Capercaillie Tetrao-Urogallus in Finland. Comparative Biochemistry and Physiology APhysiology 97:345-51.

Hofer, H., and M. L. East. 1998. Biological conservation and stress. Advances in the Study of Behavior 27:405-525.

Homyack, J. A. 2010. Evaluating habitat quality of vertebrates using conservation physiology tools. Wildlife Research 37:332-342.

Husak, J. F., and I. T. Moore. 2008. Stress hormones and mate choice. Trends in Ecology and Evolution 23:532-534.

INTOSAI WGEA (International Organization of Supreme Audit Institutions, Group on Environmental Auditing). 2013. Impact of tourism on wildlife conservation. INTOSAI Working Group on Environmental Auditing. http://www. environmental-auditing.org

Landys, M. M., M. Ramenosky, and J. C. Wingfield. 2006. Actions of glucocorticoids at a seasonal baseline as compared to stress-related levels in the regulation of periodic life processes. General and Comparative Endocrinology 148:132-149.

Langston, R. H. W., D. Liley, G. Murison, E. Woodfield, and R. T. Clarke. 2007. What effects do walkers and dogs have on the distribution and productivity of breeding European Nightjar Caprimulgus europaeus? Ibis 149:27-36.

Lee, J. 1992. Comparison of variance between correlated samples. Computer Applications in the Biosciences: CABIOS 8:405-406.

Lees, J., R. Nudds, K. A. Stokkan, L. Folkow, and J. Codd. 2010. Reduced metabolic cost of locomotion in Svalbard rock ptarmigan (Lagopus muta hyperborea) during winter. PLoS ONE 5:e15490.

Lighton, J. R. B. 2008. Measuring metabolic rates. A manual for scientists. Oxford University Press, Oxford, UK.

Lindström, A., and A. Kvist. 1995. Maximum energy intake rate is proportional to basal metabolic rate in passerine birds. Proceedings of the Royal Society B 261:337-343.

Marjakangas, A. 1986. On the winter ecology of the black grouse, Tetrao tetrix, in central Finland. Acta Universitatis Ouluensis. Series A, Scientiae rerum naturalium 183.

McEwen, B. S., and J. C. Wingfield. 2003. The concept of allostasis in biology and biomedicine. Hormones and Behavior 43:2-15.

McKechnie, A. E. 2008. Phenotypic flexibility in basal metabolic rate and the changing view of avian physiological diversity: a review. Journal of Comparative Physiology 178B:235-247.

Millspaugh, J. J., and B. E. Washburn. 2004. Use of fecal glucocorticoid metabolite measures in conservation biology research: considerations for application and interpretation. General and Comparative Endocrinology 138:189-199.

Möstl, E., and R. Palme. 2002. Hormones as indicators of stress. Domestic Animal Endocrinology 23:67-74.

Müllner, A., K. E. Linsenmair, and M. Wikelski. 2004. Exposure to ecotourism reduces survival and affects stress response in hoatzin chicks (Opisthocomus hoazin). Biological Conservation 118:549-558.

Munns, W. R. 2006. Assessing risks to wildlife populations from multiple stressors: overview of the problem and research needs. Ecology and Society 11:art 23.

Palme, R., C. Touma, N. Arias, M. F. Dominchin, and M. Lepschy. 2013. Steroid extraction: Get the best out of faecal 
samples. Wiener Tierärztliche Monatsschrift-Veterinary Medicine Austria 100:238-246.

Patthey, P., S. Wirthner, N. Signorell, and R. Arlettaz. 2008. Impact of outdoor winter sports on the abundance of a key indicator species of alpine ecosystems. Journal of Applied Ecology 45:1704-1711.

Pauli, H. R. 1974. Zur Winterökologie des Birkhuhns Tetrao tetrix in den Schweizer Alpen. Der Ornithologische Beobachter 71:247-178.

Peters, R. H. 1983. The ecological implications of body size. Cambridge University Press, Cambridge, UK.

Pinheiro, J. C., and D. M. Bates. 2000. Mixed-effects models in $\mathrm{S}$ and S-PLUS. Statistics and Computing Series. SpringerVerlag, New York, New York, USA.

R Development Core Team. 2012. R: a language and environment for statistical computing. R Foundation for Statistical Computing, Vienna, Austria.

Raouf, S. A., L. C. Smith, M. B. Brown, J. C. Wingfield, and C. R. Brown. 2006. Glucocorticoid hormone levels increase with group size and parasite load in Cliff Swallows. Animal Behaviour 71:39-48.

Rehnus, M., M. Wehrle, and R. Palme. 2014. Mountain hares (Lepus timidus) and tourism: stress events and reactions. Journal of Applied Ecology 51:6-12.

Reimers, E., S. Eftestøl, and J. E. Colman. 2003. Behavior responses of wild reindeer to direct provocation by a snowmobile or skier. Journal of Wildlife Management 67:747-754.

Reneerkens, J., T. Piersma, and M. Ramenofsky. 2002. An experimental test of the relationship between temporal variability of feeding opportunities and baseline levels of corticosterone in a shorebird. Journal of Experimental Zoology 293:81-88.

Rettenbacher, S., E. Mostl, R. Hackl, K. Ghareeb, and R. Palme. 2004. Measurement of corticosterone metabolites in chicken droppings. British Poultry Science 45:704-711.

Rintamäki, H., S. Saarela, A. Marjakangas, and R. Hissa. 1983. Summer and winter temperature regulation in the black grouse Lyrurus tetrix. Physiological Zoology 56:152-159.

Romero, L. M., M. J. Dickens, and N. E. Cyr. 2009. The reactive scope model-a new model integrating homeostasis, allostasis, and stress. Hormones and Behaviour 55:375-389.

Romero, M. 2004. Physiological stress in ecology: lessons from biomedical research. Trends in Ecology and Evolution 19:249-255.

Sapolsky, M., L. M. Romero, and A. U. Munck. 2000. How do glucocorticoids influence stress responses? Integrating permissive, suppressive, stimulatory and preparative actions. Endocrine Reviews 21:55-89.

Schmidt-Nielsen, K. 1990. Animal physiology: adaptation and environment. Fourth edition. Cambridge University Press, Cambridge, UK.

Schummer, M. L., and W. R. Eddleman. 2003. Effects of disturbance on activity and energy budgets of migrating waterbirds in south-central Oklahoma. Journal of Wildlife Management 67:789-795.

Spidsø, T. K., O. Hjeljord, and J. G. Dokk. 1997. Seasonal mortality of black grouse Tetrao tetrix during a year with little snow. Wildlife Biology 3:205-209.

Stevenson, R. D. 2006. Ecophysiology and conservation: the contribution of energetics. Introduction to the symposium. Integrative and Comparative Biology 46:1088-1092.

Stokkan, K. A. 1992. Energetics and adaptations to cold in ptarmigan in winter. Ornis Scandinavica 23:366-370.
Storch, I. 2007. Grouse. In status survey and conservation action plan 2006-2010. IUCN, The World Pheasant Association, Gland, Switzerland.

Sutherland, W. J. 2007. Future directions in disturbance research. Ibis 149:120-124.

Svensson, E., L. Råberg, C. Koch, and D. Hasselquist. 1998. Energetic stress, immunosuppression and the costs of an antibody response. Functional Ecology 12:912-919.

Taylor, A. R., and R. L. Knight. 2003. Wildlife responses to recreation and associated visitor perceptions. Ecological Applications 13:951-963.

Thiel, D., S. Jenni-Eiermann, V. Braunisch, R. Palme, and L. Jenni. 2008. Ski tourism affects habitat use and evokes a physiological stress response in capercaillie Tetrao urogallus: a new methodological approach. Journal of Applied Ecology 45:845-853.

Thomas, V. G. 1987. Similar winter energy strategies of grouse, hares and rabbits in northern biomes. Oikos 50:206-212.

Thompson, F. R., III, and E. K. Fritzell. 1988. Ruffed grouse winter roost site preference and influence on energy demands. Journal of Wildlife Management 52:454-460.

Touma, C., and R. Palme. 2005. Measuring fecal glucocorticoid metabolites in mammals and birds: the importance of validation. In Bird hormones and bird migrations: analyzing hormones in droppings and egg yolks and assessing adaptations in long-distance migration. Annals of the New York Academy of Sciences 1046:54-74.

Tucker, V. A. 1973. Bird metabolism during flight: evaluation of a theory. Journal of Experimental Biology 58:689-709.

von der Ohe, C. G., and C. Servheen. 2002. Measuring stress in mammals using fecal glucocorticoids: opportunities and challenges. Wildlife Society Bulletin 30:1215-1225.

Wasser, S. K., K. Bevis, G. King, and E. Hanson. 1997. Noninvasive physiological measures of disturbance in the Northern Spotted Owl. Conservation Biology 11:10191022.

Watson, A., and R. Moss. 2004. Impacts of ski-development on ptarmigan (Lagopus mutus) at Cairn Gorm, Scotland. Biological Conservation 116:267-275.

Weathers, W. W. 1979. Climatic adaptation in avian standard metabolic rate. Oecologia 42:81-89.

West, A. D., J. D. Goss-Custard, R. A. Stillman, R. W. G. Caldow, S. E. A. le V. dit Durell, and S. McGrorty. 2002. Predicting the impacts of disturbance on shorebird mortality using a behaviour-based model. Biological Conservation 106:319-328.

Willebrand, T., and V. Marcström. 1989. Marrow, heart and body fat as indicators of black grouse Tetrao tetrix condition. Ornis Scandinavica 20:49-52.

Williams, R., D. Lusseau, and P. S. Hammond. 2006. Estimating relative energetic costs of human disturbance to killer whales (Orcinus orca). Biological Conservation 133:301-311.

Wingfield, J. C., C. Breuner, and J. Jacobs. 1997. Corticosterone and behavioral responses to unpredictable events. Pages 267 278 in S. Harvey and R. J. Etches, editors. Perspectives in avian endocrinology. Journal of Endocrinology, Bristol, UK.

Wingfield, J. C., K. M. O'Reilly, and L. B. Astheimer. 1995. Modulation of the adrenocortical responses to acute stress in arctic birds: a possible ecological basis. American Zoologist 35:285-294.

Wingfield, J. C., and B. Silverin. 1986. Effects of corticosterone on territorial behavior of free-living male song sparrows Melospiza melodia. Hormones and Behavior 20:405-417.

\section{Supplemental Material}

\section{Ecological Archives}

The Appendix is available online: http://dx.doi.org/10.1890/14-1141.1.sm 


\section{Ecological Archives A025-071-A1}

Raphaël Arlettaz, Sébastien Nusslé, Marjana Baltic, Peter Vogel, Rupert

Palme, Susanne Jenni-Eiermann, Patrick Patthey, and Michel Genoud. 2015. Disturbance of wildlife by outdoor winter recreation: allostatic stress response and altered activity-energy budgets. Ecological Applications 25:1197-1212. http://dx.doi.org/10.1890/14-1141.1

Appendix A. A table showing the number of samples analyzed for estimating the concentration of fecal corticosterone metabolites obtained from snow burrows, a figure showing the method for extracting activity budgets from radio-tracking data, and a figure showing the relationship between respiratory metabolism and ambient temperature obtained from captive birds in the lab.

TABLE A1. Number of fecal samples analysed for estimating the concentration of stress hormone metabolites with respect to bird and experimental day (day numbers refer to the schematic view in Fig. 2).

\begin{tabular}{lrrrrr}
\hline Bird \# & Day 0 & Day 1 & Day 2 & Day 3 & Day 4 \\
\hline 1 & 10 & 10 & 0 & 0 & 10 \\
2 & 10 & 10 & 0 & 3 & 0 \\
3 & 10 & 10 & 10 & 10 & 10 \\
4 & 10 & 0 & 2 & 10 & 10 \\
5 & 10 & 9 & 10 & 10 & 0 \\
6 & 10 & 4 & 0 & 10 & 10 \\
7 & 9 & 2 & 0 & 9 & 0 \\
8 & 3 & 0 & 5 & 9 & 9 \\
9 & 1 & 10 & 10 & 10 & 10 \\
10 & 10 & 0 & 10 & 10 & 0 \\
11 & 34 & 0 & 34 & 15 & 36 \\
12 & 10 & 10 & 10 & 10 & 10 \\
\hline
\end{tabular}



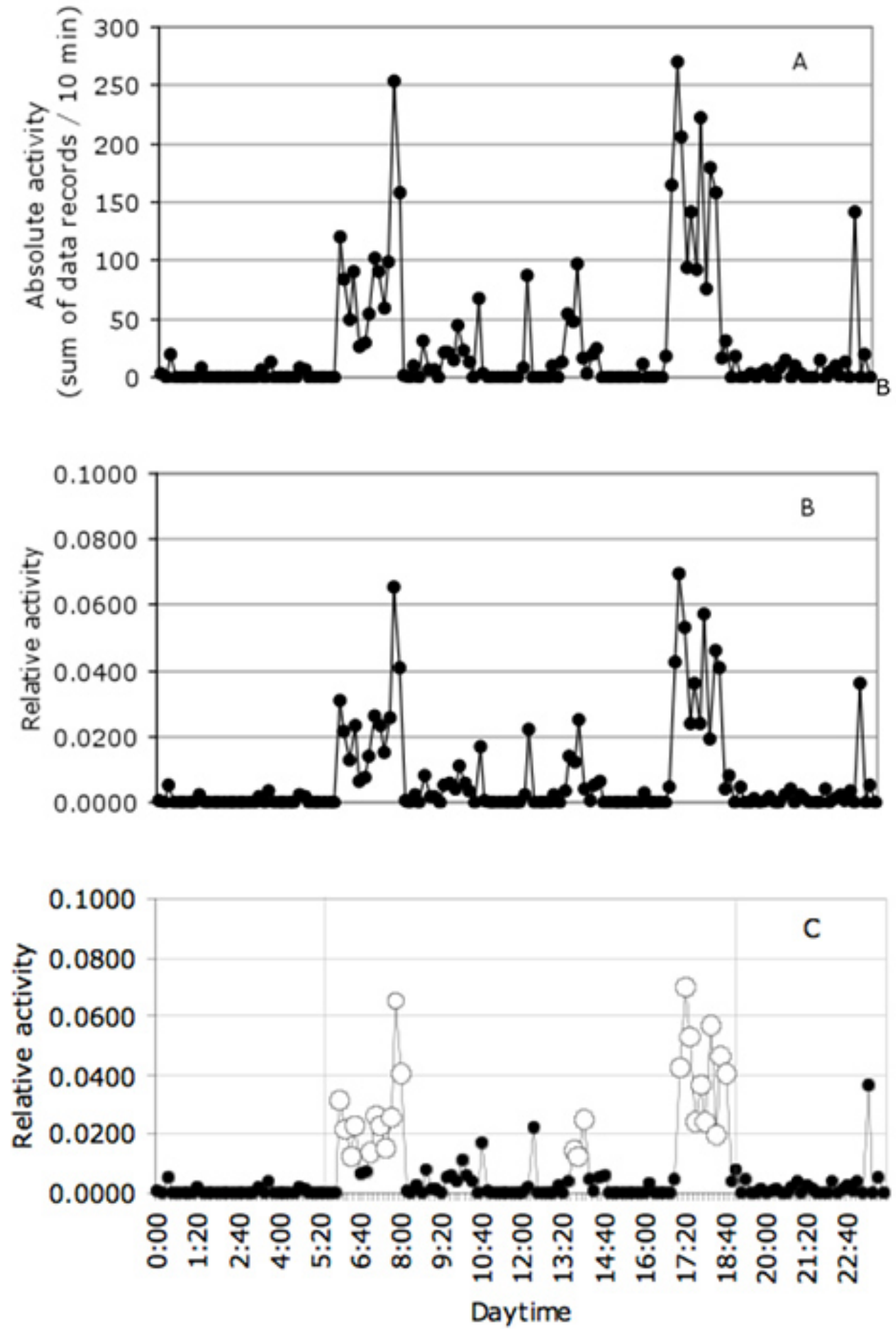

FIG. A1. Example of an absolute activity curve (A), relative activity proportion curve (B) and activity budget curve (C) for one bird in Les Diablerets on 12th March (144 daily data points, i.e., 10 min periods); white circles in $\mathrm{C}$ represent feeding sequences. The two vertical lines in $\mathrm{C}$ show daylight interval boundaries. Phases of activity corresponded almost exclusively to foraging, as backed by field visual observations. 


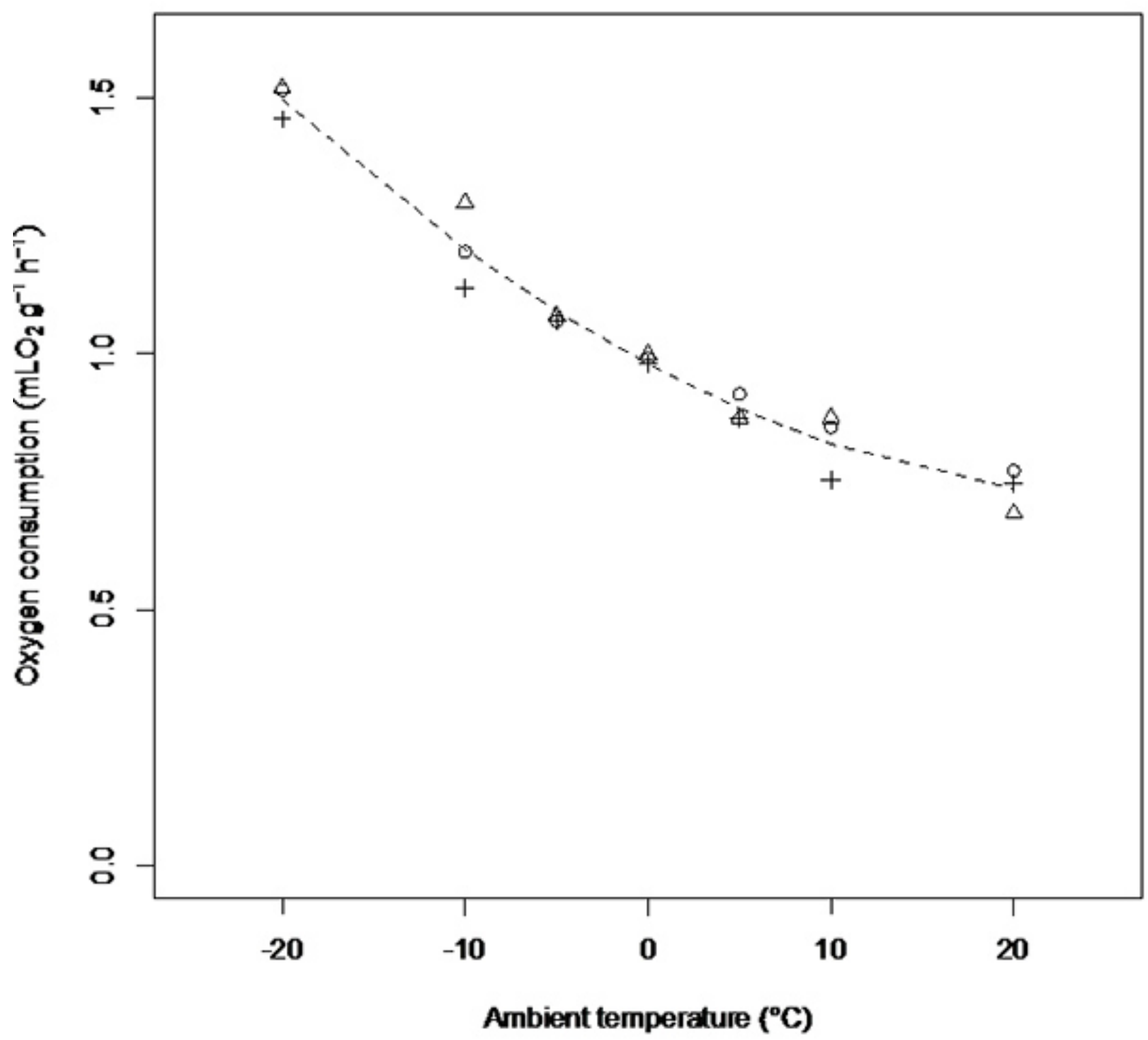

FIG. A2. Modeling of the rate of oxygen consumption as a function of ambient temperature.

We used a linear mixed model (LMM) to model rate of oxygen consumption as a function of ambient temperature for three captive black grouse cocks (different symbols on figure). We considered the factor individual as a random term, ambient temperature as a fixed term and used residual maximum likelihood estimation. Measurements made on black grouse in Finland (Rintamäki et al., 1983) have shown that the lower edge of the thermoneutral zone is close to $20^{\circ} \mathrm{C}$, thus we used values obtained at this $T_{a}\left(756 \pm 55 \mathrm{~mL} \mathrm{O}_{2} \mathrm{~h}^{-1}\right)$ as an estimate of the basal rate of metabolism. Within the range of experimental ambient temperatures, the effect of $T_{a}$ (fixed effect) on the rate of metabolism can be represented by the following quadratic equation (dashed line): $V O_{2}=0.97860-0.01898 T_{a}+0.00034\left(T_{a}\right) 2$, with standard errors of $0.01691,0.00066$ and 0.00005 for the three parameters, respectively, all of them being significant (all $p<0.01$ ). Excluding the values at $20^{\circ} \mathrm{C}$ would have only a minor effect on the above relationship. The residuals of the model were normally distributed (Shapiro-Wilk test, $W=0.97, p=0.72$ ). 